\title{
Macrophage Migration Inhibitory Factor Regulates Joint Capsule Fibrosis by Promoting TGF- $\beta 1$ Production in Fibroblasts
}

\section{Yuxin Zhang ( $\triangle$ yuxinzhang0129@163.com )}

Shanghai 9th Peoples Hospital Affiliated to Shanghai Jiaotong University School of Medicine https://orcid.org/0000-0001-7224-2533

\section{Shenji Lu}

Shanghai 9th Peoples Hospital Affiliated to Shanghai Jiaotong University School of Medicine

\section{Kexin Wang}

Shanghai University of Sport

\section{Shuai Fan}

Shanghai 9th Peoples Hospital Affiliated to Shanghai Jiaotong University School of Medicine Lili Xu

Shanghai 9th Peoples Hospital Affiliated to Shanghai Jiaotong University School of Medicine

\section{Bin Cai}

Shanghai 9th Peoples Hospital Affiliated to Shanghai Jiaotong University School of Medicine

\section{Research}

Keywords: Macrophage migration inhibitory factor, Inflammation, Fibroblasts, Transforming growth factor- $\beta 1$, Fibrosis, Joint capsule

Posted Date: December 10th, 2020

DOl: https://doi.org/10.21203/rs.3.rs-122102/v1

License: (a) (1) This work is licensed under a Creative Commons Attribution 4.0 International License. Read Full License 


\section{Abstract}

Background: Joint capsule fibrosis caused by excessive inflammation results in post-traumatic joint contracture (PTJC). Transforming growth factor (TGF)- $\beta 1$ plays a key role in PTJC by regulating fibroblast functions, however, cytokine-induced TGF- $\beta 1$ expression in specific cell types remains poorly characterized. Macrophage migration inhibitory factor (MIF) is a proinflammatory cytokine involved in inflammation- and fibrosis-associated pathophysiology.

Results: In this study, we investigated whether MIF can facilitate TGF- $\beta 1$ production from fibroblasts and regulate joint capsule fibrosis following PTJC. Our data demonstrated that MIF and TGF- $\beta 1$ significantly increased in fibroblasts of injured rat posterior joint capsules. Treatment the lesion sites with MIF inhibitor 4-lodo-6-phenylpyrimidine (4-IPP) reduced TGF- $\beta 1$ production and relieved joint capsule inflammation and fibrosis. In vitro, MIF facilitated TGF- $\beta 1$ expression in primary joint capsule fibroblasts by activating mitogen-activated protein kinase (MAPK) (P38, ERK) signaling through coupling with membrane surface receptor $\mathrm{CD} 74$, which in turn affected fibroblast functions and promoted MIF production.

Conclusion: Our results reveal a novel function of trauma-induced MIF in the occurrence and development of joint capsule fibrosis. Further investigation of the underlying mechanism may provide potential therapeutic targets for PTJC.

\section{Background}

Post-traumatic joint contracture (PTJC) is a major chronic musculoskeletal complication of joint injury and osteoarthritis [1-3], which seriously affects patients' quality of life and social productivity [2]. Joint capsule fibrosis underlies the pathogenesis of PTJC, and is caused by inflammation, extracellular matrix (ECM) deposition, and collagen hyperplasia and arrangement disorder, together with other factors [3-5]. As the main cell types in joint capsules, fibroblasts play a key role in ECM synthesis and remodeling, as well as inflammation and immune regulation [6]. Under pathological conditions such as injury or inflammation, immune cells rapidly activate and secrete various cytokines, including transforming growth factor- $\beta$ (TGF- $\beta$ ), interleukin (IL)-13, and platelet-derived growth factor (PDGF) [6-8]. Secreted cytokines in turn promote fibroblast activation, proliferation, migration, differentiation into myofibroblasts expressing a-smooth muscle actin (a-SMA), and fibrotic factor production [5, 9]. Modulation of these fibroblast events renders TGF- $\beta 1$ a key regulator of joint capsule inflammation and fibrosis. TGF- $\beta 1$ levels are chronically elevated in patients and animals with PTJC, and blocking TGF- $\beta 1$ expression during joint trauma is an effective treatment strategy to reduce the severity of joint capsule fibrosis $[10,11]$. However, the mechanism underlying specific cytokine-induced TGF- $\beta 1$ expression in distinct cell types during PTJC has not been fully elucidated.

Macrophage migration inhibitory factor (MIF) is a multifunctional proinflammatory cytokine ubiquitously distributed in various neurons, astrocytes, immune cells, endothelial cells, hepatocytes, and fibroblasts [12-14]. In higher mammals, MIF regulates the pathophysiological processes of immunity, inflammation, 
wound healing, and cell proliferation and migration, and is therefore involved in numerous inflammationand fibrosis-related diseases, including systemic infections, sepsis, osteoarthritis, rheumatoid arthritis, and atherosclerosis by regulating the pathophysiological processes of immunity, inflammation, wound healing, and cell proliferation and migration [15-17]. Consequently, MIF has become a potential therapeutic target for these diseases. In chronic inflammatory diseases such as myocardial infarction, atrial fibrillation, and cystic fibrosis, MIF expression is increased, which promotes fibroblast proliferation and expression of fibrosis-related factors, especially TGF- $\beta 1[15,18,19]$. MIF exerts its physiological functions by interacting with membrane receptor $C D 74$, which forms a receptor complex with chemokine receptors CXCR2, CXCR4, or CXCR7 to activate multiple intracellular signaling cascades [20]. We previously found that the MIF/CD74 axis promotes the production of PGE2 via activating mitogenactivated protein kinase (MAPK) signaling in astrocytes, thus regulating the inflammatory microenvironment of injured tissues [21]. We therefore hypothesized that TGF- $\beta 1$-modulated pathological fibroblast functions may be associated with the activation of the MIF/CD74 axis, through which it regulates joint capsule fibrosis. In the present study, we examined the relationship between the expression of MIF and TGF- $\beta 1$ in injured posterior joint capsules following PTJC in rats. We further investigated the effect of MIF on TGF- $\beta 1$ expression in joint capsule fibroblasts as well as the underlying molecular mechanism. Our results revealed that the MIF/CD74 axis affects pathological changes of joint capsule fibrosis by modulating TGF- $\beta 1$ in joint capsule fibroblasts during PTJC.

\section{Results}

\section{Injury-induced MIF promotes TGF- $\beta 1$ expression in joint capsule fibroblasts following PTJC}

First, we established the rat knee joint PTJC model (Additional file 1: Fig. S1a) and measured the knee passive extension ROM (normal saline group). The normal knee extension ROM was $159.2 \pm 3.4^{\circ}$, but was reduced to $157.1 \pm 1.2^{\circ}, 151.8 \pm 1.7^{\circ}, 130.3 \pm 2.9^{\circ}$, and $96.8 \pm 2.0^{\circ}$ at $1,3,7$, and 14 days post-induction of PTJC, respectively (Additional file 1: Fig. S1b). Histological analyses of the posterior joint capsule revealed increased numbers and density of inflammatory cells (HE), along with collagen fiber hyperplasia and disordered arrangement (Masson) (Additional file 1: Fig. S1c). These changes are mirror those found in humans and indicate that inflammation and fibrosis are closely related to PTJC.

To examine whether MIF expression correlates with TGF- $\beta 1$ production by joint capsule fibroblasts, we assayed the levels of these cytokines in the posterior joint capsule following PTJC at $0,1,3,7$, and 14 days (normal saline group) (Fig. 1). Western blot analysis revealed that expression of MIF and TGF- $\beta 1$ was induced following PTJC. MIF levels peaked on the third day and TGF- $\beta 1$ expression increased in a time-dependent manner (Fig. 1a). To identify the specific cell types that respond to MIF, we performed immunostaining. MIF and TGF- $\beta 1$ co-localized with vimentin-positive fibroblasts (Fig. 1b, 1c). Consistent with the results of western blot, the fluorescence intensity of MIF and TGF- $\beta 1$ was markedly enhanced after joint injury, indicating that the production of MIF and TGF- $\beta 1$ was synchronous with the activation 
of fibroblasts. Injection of MIF inhibitor 4-IPP at the lesion sites significantly decreased the expression of MIF (Additional file 1: Fig. S2) and TGF- $\beta 1$ in fibroblasts (Fig. 2a, 2b), which attenuated joint capsule fibrosis. These data indicate that injury-induced MIF is able to facilitate TGF- $\beta 1$ expression in fibroblasts following PTJC.

\section{MIF facilitates TGF- $\beta 1$ expression in primary joint capsule fibroblasts in vitro}

To validate the role of MIF in regulating TGF- $\beta 1$ expression in fibroblasts, primary joint capsule fibroblasts were cultured and treated with $0-2.5 \mu \mathrm{g} / \mathrm{mL}$ recombinant MIF for $24 \mathrm{~h}$ (Fig. 3a). As shown by CCK-8, MIF slightly enhanced cell viability (Fig. 3b), indicating that this concentration range was applicable to subsequent experiments. We then detected the expression of TGF- $\beta 1$ at both the transcriptional and translational levels. qRT-PCR and western blot demonstrated that TGF- $\beta 1$ significantly increased in MIFtreated fibroblasts in a dose-dependent manner (Fig. 3c, 3e). In addition, the fluorescence intensity of TGF- $\beta 1$ was markedly enhanced in fibroblasts after $2 \mu \mathrm{g} / \mathrm{mL}$ MIF treatment (Fig. 3d). Addition of $50 \mu \mathrm{M}$ 4-IPP to the culture efficiently blocked the effects of $2 \mu \mathrm{g} / \mathrm{mL}$ MIF on TGF- $\beta 1$ expression (Fig. 4a-4c). These results indicate that MIF induces TGF- $\beta 1$ expression in joint capsule fibroblasts.

\section{MIF regulates TGF- $\beta 1$ expression in fibroblasts through membrane receptor CD74}

Next, to clarify whether MIF interacts with CD74 in joint capsule fibroblasts and whether this interaction is associated to MIF-induced TGF- $\beta 1$ production, we performed Co-IP using anti-MIF and anti-CD74 antibodies. As shown in Fig. 5a, CD74 was detected in the MIF-associated complexes. Conversely, MIF was also co-precipitated in CD74-associated complexes, indicating that MIF can bind to the CD74 receptor of joint capsule fibroblasts. Subsequently, we synthesized and evaluated three specific small interfering RNA (siRNA) targeting CD74 (RiboBio, Guangzhou, China) to knockdown its endogenous expression [21]. SiRNA2, showing the highest interference efficiency, was selected for subsequent experiments (Fig. 5b). Fibroblasts were transfected with siRNA2 for $48 \mathrm{~h}$, followed by treatment with $2 \mu \mathrm{g} / \mathrm{mL}$ MIF for $24 \mathrm{~h}$. Western blot analysis showed that CD74 silencing resulted in a significant decrease in TGF- $\beta 1$ expression at the protein level (Fig. $5 \mathrm{c}$ ). These findings suggest that MIF-induced TGF- $\beta 1$ expression in joint capsule fibroblasts is dependent on the CD74 membrane receptor.

\section{MIF promotes TGF- $\beta 1$ production through P38 and ERK signaling}

To pinpoint the relevant pathway through which MIF regulates TGF- $\beta 1$ production, we performed transcriptome sequencing analysis on primary joint capsule fibroblasts treated with $2 \mu \mathrm{g} / \mathrm{mL}$ recombinant MIF for 24 and $48 \mathrm{~h}$. Then, KEGG function enrichment analysis was performed for all the DEGs at the two time points (Additional file 1: Fig. S3, S4). KEGG pathway analysis revealed that chemotactic signaling, inflammatory response, and related MAPK cascades were included in the top 15 significantly enriched functional pathways (Fig. 6a-6c). Consistent with transcriptome analysis, western 
blot showed that phosphorylation of MAPK signaling components (ERK, P38, and JNK) was rapidly induced 15 min after stimulation of joint capsule fibroblasts with $2 \mu \mathrm{g} / \mathrm{mL}$ recombinant MIF (Fig. $6 \mathrm{~d}-6 \mathrm{f}$ ). The MAPK pathway is a crucial intracellular signaling cascade that mediates MIF function [22, 23]. To determine whether expression of TGF- $\beta 1$ by MIF was associated with MAPK, we silenced the CD74 receptor in joint capsule fibroblasts and treated them with $2 \mu \mathrm{g} / \mathrm{mL}$ recombinant MIF for $30 \mathrm{~min}$. Knockdown of CD74 led to a significant decrease in ERK, P38, and JNK phosphorylation levels (Fig. 7a7c). Subsequently, joint capsule fibroblasts were treated with inhibitors of P38 (SB203580, TOCRIS), JNK (SP600125, TOCRIS), and ERK (PD98059, TOCRIS) in the presence of $2 \mu \mathrm{g} / \mathrm{mL}$ recombinant MIF. Interestingly, TGF- $\beta 1$ production was exclusively attenuated by treatment with ERK and P38 inhibitors, rather than by the JNK inhibitor (Fig. 7d). These data indicate that MIF-induced TGF- $\beta 1$ production in joint capsule fibroblasts is regulated by ERK and P38 pathways.

\section{High TGF- $\beta 1$ concentrations induce MIF expression}

A large number of studies have shown that TGF- $\beta 1$ can promote the differentiation of fibroblasts into myofibroblasts, collagen hyperplasia, and ECM protein accumulation [11]. Consistent with this, we confirmed that $10 \mathrm{ng} / \mathrm{mL}$ TGF- $\beta 1$ promotes the expression of myofibroblast marker a-SMA, collagen I, as well as its own expression in joint capsule fibroblasts (Fig. 8a). In a study, it was found that growth factors such as TGF- $\beta$ can significantly upregulate the expression of MIF in mouse osteoblast cell lines [24]. To explore whether TGF- $\beta 1$ could also regulate MIF, we stimulated joint capsular fibroblasts with different concentrations of TGF- $\beta 1$ for $24 \mathrm{~h}$. As shown in Fig. 8b, TGF- $\beta 1$ treatment did not affect cell viability. However, 50 and $100 \mathrm{ng} / \mathrm{mL}$ TGF- $\beta 1$ significantly induced the expression of MIF (Fig. 8c, 8d). These data indicate that when MIF-induced release of TGF- $\beta 1$ accumulation to certain concentrations could lead to MIF induction, thus forming a positive feedback loop promoting inflammation and fibrosis during PTJC.

\section{Discussion}

PTJC is the main musculoskeletal disease caused by trauma or surgery and is characterized by irreversible loss of joint motion $[1,25]$. The development of PTJC is a complex pathological process accompanied by structural changes in the joints and surrounding tissues. Among these, posterior joint capsule fibrosis is the key anatomic factor underlying PTJC [3-5]. Joint trauma triggers edema, bleeding, and inflammatory response, during which the resident and infiltrating immune and stromal cells are rapidly prompted to release various cytokines and chemokines $[4,626]$. These factors converge into a complex network to jointly regulate the fibrosis process. Activated fibroblasts, as key cell mediators, advance this process through hyperproliferation, differentiation into myofibroblasts, regulation of ECM components, and inflammation [27]. In addition, fibroblasts constitutively express a series of innate immune receptors and are therefore highly sensitive to infections or tissue damage [28-30]. TGF- $\beta 1$ is considered the most critical cytokine promoting fibrosis by affecting fibroblast functions [31-33]. Despite the fact that TGF- $\beta 1$ is upregulated in animal PTJC models and its inhibition can relieve joint capsule 
fibrosis $[11,1234,35]$, the precise mechanisms orchestrating TGF- $\beta 1$ production are not yet well understood.

Several cytokines have been reported to be responsible for inducing TGF- $\beta 1$ expression in immune cells through multiple signaling pathways $[6,8,26]$. MIF is constitutively expressed in various immune and non-immune cells of different histogenetic origins and can be induced by injury signals $[13,14]$. MIF shows a remarkable functional diversity, ranging from promoting pattern recognition receptor TLR-4 expression, enhancing inflammatory cell recruitment, and inhibiting p53-mediated cell apoptosis to eliminating the anti-inflammatory effects of glucocorticoids [12-14]. Given such broad activities, it is not surprising that aberrant expression of MIF is implicated in several diseases. While previous studies on MIF-mediated chronic inflammation and fibrosis were mainly focused on the skin and different organs $[15,18$ 19], its role in PTJC has not been previously reported. In the current study, we show that MIF is induced in the posterior joint capsule after PTJC and that increased MIF promotes TGF- $\beta 1$ expression in fibroblasts, providing a novel mechanism for joint capsule fibrosis following PTJC.

MIF plays a pivotal role in regulating fibrosis of visceral organs such as the heart, liver, and lung by interacting with its high-affinity membrane receptor CD74 [36-38]. Similarly, in this study, we similarly found that the MIF/CD74 axis can activate TGF- $\beta 1$ expression in joint capsule fibroblasts, indicating the conserved regulatory mechanism of MIF in different cell types. Numerous signaling pathways are involved in tissue fibrosis, including MAPK, NF-KB, TGF- $\beta 1 / S M A D$, and Wnt/ $\beta$-catenin signaling [39]. To unveil the mechanism by which MIF induces TGF- $\beta 1$ expression, we performed transcriptome analysis on MIF-treated joint capsule fibroblasts. KEGG pathway analysis revealed significant enrichment of the MAPK pathway, the main intracellular signal transduction pathway regulating cell proliferation, differentiation, survival, and apoptosis [40]. The ERK signaling pathway is involved in urethral plate fibroblasts proliferation, apoptosis, and regulation of the cell cycle [41]. Phosphorylation of P38 and JNK promotes proliferation of lung mesenchymal fibroblasts [42]. We previously found that the MIF/CD74 axis regulates the inflammatory microenvironment of injured tissues via activating MAPK signaling (P38, JNK, ERK) in astrocytes [21]. In the present study, we revealed a novel role of the MIF/CD74 axis in facilitating TGF- $\beta 1$ production in joint capsule fibroblasts through activation of ERK and P38.

TGF- $\beta 1$ is an effective fibroblast activator and mitogen, as well as a key signal for fibroblast differentiation and collagen synthesis $[43,44]$. Consistent with these studies, we illustrate that treatment of joint capsule fibroblasts with TGF- $\beta 1$ not only upregulated the levels of a-SMA and collagen I, but also the levels of TGF- $\beta 1$ itself. This may be the reason why TGF- $\beta 1$ expression increased in a time-dependent manner after PTJC, although MIF expression reached its peak on the third day. Interestingly, we also found that high concentrations of TGF- $\beta 1$ significantly increased MIF expression at the MRNA and protein levels, suggesting that TGF- $\beta 1$ accumulation in the lesion sites can in turn induce MIF, which may form a positive feedback loop promoting joint capsule inflammation and fibrosis. However, the related mechanisms remain to be further clarified.

\section{Conclusions}


Our data demonstrate that MIF protein levels increase following PTJC, which promotes TGF- $\beta 1$ expression from joint capsule fibroblasts through interaction with CD74 receptor and subsequent activation of P38 and ERK pathways. TGF- $\beta 1$ in turn facilitates fibroblast differentiation and MIF production, thus generating a positive feedback loop regulating joint capsule inflammation and fibrosis during PTJC.

\section{Methods}

\section{Animals}

Adult male Sprague Dawley (SD) rats (6 weeks old, 180-220 g) were purchased from Shanghai SIPPR-Bk Lab Animal Co., Ltd. and maintained in specific pathogen-free laboratory animal facilities of the Ninth People's Hospital Affiliated to Shanghai Jiao Tong University School of Medicine. All rats were acclimated to the facility for seven days before in vivo experiments. All animal experiments complied with the National Institutes of Health Guide for the Care and Use of Laboratory Animals and were reviewed and approved by the Institution of Animal Care and Use Committee (IACUC) of the Ninth People's Hospital Affiliated to Shanghai Jiao Tong University School of Medicine. All animals were housed in individual cages under a 12 -h light/dark cycle at room temperature $\left(23 \pm 1{ }^{\circ} \mathrm{C}\right)$ with free access to food and water.

\section{Establishment of rat PTJC model}

The number of surgically treated animals was calculated as 6 per experimental group. The PTJC model was established based on previous research [45]. Briefly, rats were anesthetized with an intraperitoneal injection of sodium pentobarbital ( $50 \mathrm{mg} / \mathrm{kg}$ ), placed in supine position, and prepared for surgery under aseptic conditions. The fur was shaved from the surgical site of the right knee joint, and the skin was disinfected with chlorhexidine. A 15-mm midline skin incision was made, and a lateral parapatellar arthrotomy was performed. The patella was reflected medially and the femoral condyles were exposed. Two cortical windows $1.5-\mathrm{mm}$ in diameter were made from the non-articulating cartilaginous regions of the medial and lateral femoral condyles using a $1.5-\mathrm{mm}$ drill bit. The anterior/posterior cruciate ligament was sequentially incised and the knee joint hyperextended to $-45^{\circ}$ to disrupt the posterior capsule. The right knee joint was immobilized at approximately $135^{\circ}$ of flexion with a $0.5-\mathrm{mm}$ steel wire. The muscles and skin were sutured with silk threads after the patellofemoral joint reduction. For drug delivery, $10 \mu \mathrm{L}$ of $100 \mathrm{mM}$ 4-IPP (TOCRIS, Bristol, UK) or vehicle (normal saline) was injected into the joint cavity. After the surgery, the rats received sodium salicylate $(150 \mathrm{mg} / \mathrm{kg})$ for pain control, and unrestricted daily activity in cages was permitted. Rats were euthanized at $0,1,3,7$, and 14 days, the internal fixation was removed, and the range of motion (ROM) of the knee joint extension was measured using a mechanical goniometer (arthrometer) after myotomies of the trans-articular muscles, as has been described previously [46]. Briefly, the lateral femoral condyle acted as the center of rotation and was pinned, while the proximal femur and distal tibia were attached to the two arms of the arthrometer. During motion, the two femoral points were fixed while the distal tibia could accommodate for translation at the knee joint. The reproducibility to repeated measures was within $\pm 4^{\circ}$. Conditions of temperature $\left(21^{\circ} \mathrm{C}\right)$ and angular 
velocity $(3 \% \mathrm{sec})$ were standard. ROM measurements in flexion and extension were performed at the torques of $667 \mathrm{~g} / \mathrm{cm}$. All measurements were made within $15 \mathrm{~min}$ after euthanasia. Posterior joint capsules were collected after ROM measurement for subsequent assays.

\section{Primary joint capsule fibroblasts culture}

To isolate primary joint capsule fibroblasts, SD rats (male, 4 weeks old) were sacrificed by an anesthesia overdose and disinfected in $75 \%$ alcohol for 10 min. Posterior joint capsule tissues were washed with minimum essential medium (MEM; Invitrogen, Carlsbad, CA, USA). Sub-sectioned tissues were placed in tissue culture plates containing Dulbecco's minimum essential medium (DMEM; HyClone, Logan, USA) supplemented with $10 \%$ fetal bovine serum (Gibco, Grand Island, NY, USA), $100 \mathrm{U} / \mathrm{mL}$ penicillin (Gibco), and $100 \mu \mathrm{g} / \mathrm{mL}$ streptomycin (Gibco) in a $5 \% \mathrm{CO}_{2}$ incubator at $37^{\circ} \mathrm{C}$ to obtain joint capsule fibroblasts [47]. After 3-5 days, fibroblasts started to migrate from the sub-sections. The tissues were removed when the culture reached approximately $90 \%$ confluence. The medium was changed every two days. Primary joint capsule fibroblasts were cultured to passages 2 to 4 and identified by immunofluorescence staining with vimentin (Abcam, Cambridge, UK, 1:1000) before used in subsequent experiments.

\section{Western blot}

Samples of the posterior joint capsule collected at $0,1,3,7$, and 14 days following injury or primary joint capsule fibroblasts treated with various drugs were lysed in RIPA buffer (Beyotime, Shanghai, China) supplemented with $1 \mathrm{mM}$ PMSF (Beyotime). Protein concentration was detected using the Bradford method to ensure equal loading. Western blots were performed as described previously [21]. The relative intensities of protein bands were normalized to those of $\beta$-actin. The following antibodies were used: $\beta$ actin (ProteinTech, Wuhan, China, 1:5000), MIF (Abcam, 1:1000), TGF- $\beta 1$ (Abcam, 1:1000), a-smooth muscle actin (a-SMA, Abcam, 1:1000), Collagen $\otimes$ (Abcam, 1:1000), CD74 (Santa Cruz, CA, 1:100), pERK/ERK (Cell Signaling Technology, Danvers, MA, 1:1000), p-P38/P38 (Cell Signaling Technology, 1:1000), p-JNK/JNK (Cell Signaling Technology, 1:1000). Secondary antibodies included goat anti-rabbit IgG or goat anti-mouse IgG (Invitrogen, 1:30000).

\section{Co-immunoprecipitation (Co-IP)}

Cell lysates were harvested and centrifuged at 14,000 rpm for 20 min to remove the debris after primary joint capsule fibroblast treatment with $2 \mu \mathrm{g} / \mathrm{mL}$ MIF (ProSpec, USA) for $24 \mathrm{~h}$. Protein concentration in the supernatant was quantified using the Protein Assay Kit II (Bio-Rad, Inc., California, USA). For immunoprecipitation analysis, total cell lysates $(500 \mu \mathrm{g})$ were precleared with protein A plus G-Sepharose (Beyotime) before incubation with specific antibodies at $4{ }^{\circ} \mathrm{C}$, followed by addition of protein A plus GSepharose. After several washes, samples were boiled and analyzed by immunoblotting using anti-MIF or anti-CD74 antibody.

\section{Quantitative RT-PCR}

RNA from different groups of primary joint capsule fibroblasts were extracted using TRIzol (Invitrogen) according to the manufacturer's instructions. Next, $1 \mu \mathrm{g}$ of total RNA per sample was used to synthesize 
cDNA using the Omniscript reverse transcription kit (QIAGEN, Dusseldorf, Germany), and qPCR was carried out using SYBR ${ }^{\circledR}$ Premix Ex Taq ${ }^{\text {TM }}$ (Takara Bio, Dalian, China) on a real-time PCR system (Applied Biosystems). We normalized gene expression to Gapdh levels and calculated the relative levels using

$2^{-\triangle \Delta C t}$. All reactions were performed in triplicates. The primers were designed and synthesized by Sangon Biotech (Shanghai, China) as follows: Gapdh: forward primer 5囚-ACA GCA ACA GGG TGG TGG AC-3囚, reverse primer 5囚-TTT GAG GGT GCA GCG AAC TT-3囚; Mif. forward primer 5囚-CTT GGG TCA CAC CGC

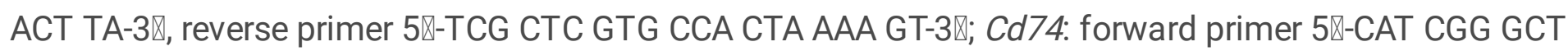

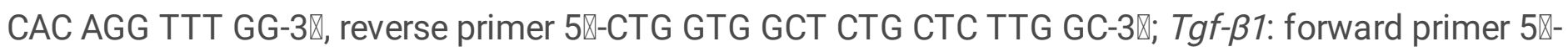
AGC AAC AAT TCC TGG CGT TAC-3囚, reverse primer 5囚-TGT ATT CCG TCT CCT TGG TTC A-3囚.

\section{Immunofluorescence}

Following treatment with $2 \mu \mathrm{g} / \mathrm{mL}$ MIF in the presence or absence of $50 \mu \mathrm{M}$ 4-IPP for $24 \mathrm{~h}$, primary joint capsule fibroblasts were fixed in $4 \%$ paraformaldehyde with $0.1 \%$ Triton X-100 (Sigma, St Louis, MO, USA) and subsequently incubated with $4 \%$ goat serum to block nonspecific binding. Then, cells were incubated with anti-TGF- $\beta 1$ (Servicebio, Wuhan, China, 1:100) primary antibodies overnight. Fluorescent secondary antibodies of FITC-labeled goat anti-rabbit IgG (Sigma, 1:400) were used to visualize the corresponding subsets. Cells were then stained with 4,6-diamidino-2-phenylindole (DAPI; Sigma, 1:4000) and phalloidin (Abcam, 1:1000), followed by observation under a confocal fluorescence microscope (Leica, Germany).

\section{Histological observation}

Knee joint samples were collected from experimental models at different time points, fixed in $4 \%$ paraformaldehyde, decalcified in 10\% EDTA, and then embedded in paraffin. The knee joint specimens were sagittally sectioned $(5 \mu \mathrm{m})$ and processed with hematoxylin-eosin (HE) and Masson trichrome staining. For immunohistochemical staining, the sections were co-incubated with antibodies against MIF (Abcam, 1:100), TGF- $\beta 1$ (Servicebio, 1:100), and vimentin (Abcam, 1:1000). The sections were further incubated with FITC-labeled goat anti-mouse IgG (Gibco, 1:400), Cy3-labeled goat anti-rabbit IgG (Sigma, 1:400), and DAPI (Sigma, 1:4000). Zeiss LSM710 confocal microscope was used for confocal imaging of samples at an original magnification $\times 40$. Confocal images were prepared with Zen software. All images were taken from similar areas of the posterior joint capsule.Three sequential specimens in each group were measured.

\section{Cell viability assay}

Primary joint capsule fibroblasts were seeded at a density of $2 \times 10^{4}$ cells/well. Cells were treated with different concentrations of MIF $(0-2.5 \mu \mathrm{g} / \mathrm{mL}$ ) or TGF- $\beta 1$ (ImmunoClone, Houston, USA, $0-100 \mathrm{ng} / \mathrm{mL}$ ) for $24 \mathrm{~h}$. Then, $10 \mu \mathrm{L}$ of Cell Counting Kit-8 (CCK-8; Dojindo, Kumamoto, Japan) was added to the cells and incubated for an additional $2 \mathrm{~h}$ at $37^{\circ} \mathrm{C}$. Cell viability was measured spectrophotometrically at $450 \mathrm{~nm}$. Assays were performed three times using triplicate wells.

\section{Sequencing of mRNA and bioinformatics analysis}


Total RNA of primary joint capsule fibroblasts following treatment with $2 \mu \mathrm{g} / \mathrm{mL}$ MIF for $24 \mathrm{~h}$ or $48 \mathrm{~h}$ was extracted using the mirVana miRNA Isolation Kit (Ambion, Texas, USA) and then selected by RNA Purification Beads (Illumina, California, USA) for library construction and RNA-seq analysis. The library was constructed using the Illumina TruSeq RNA Sample Prep Kit v2 and sequenced by the Illumina HiSeq2000 for 50 cycles. High-quality reads that passed the Illumina quality filters were used for sequence analysis. Sequencing outcomes were normalized with Reads Per Kilobase per Million mapped reads (RPKM). Differentially expressed genes (DEGs) were designated according to criteria of fold change $>2$ and false discovery rate $<0.05$ compared to the control. Gene functions were annotated by Blastx against the NCBI database or the AGRIS database with an E-value threshold of $10^{-5}$. Gene ontology (GO) classification was obtained by WEGO via GO id annotated using the Perl and R programs. The Kyoto Encyclopedia of Genes and Genomes (KEGG) pathways were assigned to the sequences using the KEGG Automatic Annotation Server (KAAS) online.

\section{Statistical analysis}

All results were expressed as the mean \pm standard deviation after analysis by the SPSS 22.0 statistical software (SPSS Inc., Chicago, IL, USA). Parametric data were analyzed by Student's t-test or one-way analysis of variance (ANOVA) followed by post-hoc Tukey's test to compare two groups. A level of $p<$ 0.05 was considered statistically significant.

\section{Abbreviations}

Co-IP: co-immunoprecipitation; ERK: extracellular regulated protein kinases; FBS: fetal bovine serum; GAPDH: glyceraldehyde 3-phosphate dehydrogenase; H\&E: hematoxylin and eosin; JNK: c-Jun N-terminal kinase; MAPK: mitogen-activated protein kinase; MIF: macrophage migration inhibitory factor; PTJC: posttraumatic joint contracture; qPCR: Quantitative polymerase chain reaction; TGF- $\beta 1$ : transforming growth factor- $\beta 1$.

\section{Declarations}

\section{Acknowledgments}

We would like to thank Editage (http://www.editage.cn) for English language editing.

\section{Authors' contributions}

$Y x Z$ and $B C$ designed this study. $Y x Z$ wrote the paper. $Y x Z, S j L$, and $K x W$ performed the experiments. $Y x Z$, $S j L, S F, L I X$, and $K x W$ analyzed the data. $Y x Z$ and $B C$ contributed to the interpretation of the results, critically revised the manuscript for important intellectual content, and approved the final version of the manuscript. All authors read and approved the final manuscript 


\section{Funding}

This study was funded by the National Key R\&D Program of China (2018YFC2001300), the Science and Technology Committee of Fengxian District, Shanghai (20201501), and the Fundamental Research Program funding of Ninth People's Hospital affiliated to Shanghai Jiao Tong University School of Medicine (JYZZ078, JYZZ033).

\section{Availability of data and materials}

The datasets used and/or analysed during the current study are available from the corresponding author on reasonable request.

\section{Ethics approval and consent to participate}

The protocol of current study was approved by the Institution of Animal Care and Use Committee (IACUC) of the Ninth People's Hospital Affiliated to Shanghai Jiao Tong University School of Medicine.

\section{Consent for publication}

Not applicable.

\section{Competing interests}

The authors declare that they have no competing interests.

\section{Author details}

${ }^{1}$ Department of Rehabilitation Medicine, Shanghai Ninth People's Hospital Affiliated to Shanghai Jiao Tong University School of Medicine, Huangpu District, Shanghai 200011, China. ${ }^{2}$ Shanghai Key Laboratory of Orthopedic Implants, Shanghai Ninth People's Hospital, Shanghai Jiao Tong University School of Medicine, Shanghai 200011, China. ${ }^{3}$ School of Kinesiology, Shanghai University of Sport, Yangpu District, Shanghai 200438, China.

\section{References}

1. Filh GM, Galvão MV. POST-TRAUMATIC STIFFNESS OF, THE ELBOW. Rev Bras Ortop. 2015;45:34754.

2. Hildebrand KA, Sutherland C, Zhang M. Rabbit knee model of post-traumatic joint contractures: the long-term natural history of motion loss and myofibroblasts. J Orthop Res. 2004;22:313-20.

3. Zhou Y, Zhang QB, Zhong HZ, Liu Y, Li J, Lv H, et al. Rabbit Model of Extending Knee Joint Contracture: Progression of Joint Motion Restriction and Subsequent Joint Capsule Changes after Immobilization. J Knee Surg. 2020;33:15-21. 
4. Lieberthal J, Sambamurthy N, Scanzello CR. Inflammation in joint injury and post-traumatic osteoarthritis. Osteoarthritis Cartilage. 2015;23:1825-34.

5. Wynn TA, Ramalingam TR. Mechanisms of fibrosis: therapeutic translation for fibrotic disease. Nat Med. 2012;18:1028-40.

6. Van Linthout S, Miteva K, Tschöpe C. Crosstalk between fibroblasts and inflammatory cells. Cardiovasc Res. 2014;102:258-69.

7. Li MO, Wan YY, Sanjabi S, Robertson AK, Flavell RA. Transforming growth factor-beta regulation of immune responses. Annu Rev Immunol. 2006;24:99-146.

8. Wynn TA. IL-13 effector functions. Annu Rev Immunol. 2003;21:425-56.

9. Leask A, Abraham DJ. TGF-beta signaling and the fibrotic response. FASEB J. 2004;18:816-27.

10. Hildebrand KA, Zhang M, Hart DA. Myofibroblast upregulators are elevated in joint capsules in posttraumatic contractures. Clin Orthop Relat Res. 2007;456:85-91.

11. Mattyasovszky SG, Wollstädter J, Martin A, Ritz U, Baranowski A, Ossendorf C, et al. Inhibition of Contractile Function in Human Joint Capsule Myofibroblasts by Targeting the TGF- $\beta 1$ and PDGF Pathways. PLoS One. 2016;11:e0145948.

12. Kang I, Bucala R. The immunobiology of MIF: function, genetics and prospects for precision medicine. Nat Rev Rheumatol. 2019;15:427-37.

13. Gilliver SC, Emmerson E, Bernhagen J, Hardman MJ. MIF: a key player in cutaneous biology and wound healing. Exp Dermatol. 2011;20:1-6.

14. Calandra T, Roger T. Macrophage migration inhibitory factor: a regulator of innate immunity. Nat Rev Immunol. 2003;3:791-800.

15. Voss S, Krüger S, Scherschel K, Warnke S, Schwarzl M, Schrage B, et al. Macrophage Migration Inhibitory Factor (MIF) Expression Increases during Myocardial Infarction and Supports ProInflammatory Signaling in Cardiac Fibroblasts. Biomolecules. 2019;9:38.

16. Verschuren L, Kooistra T, Bernhagen J, Voshol PJ, Ouwens DM, van Erk M, et al. MIF deficiency reduces chronic inflammation in white adipose tissue and impairs the development of insulin resistance, glucose intolerance, and associated atherosclerotic disease. Circ Res. 2009;105:99-107.

17. Morand EF, Leech M, Bernhagen J. MIF: a new cytokine link between rheumatoid arthritis and atherosclerosis. Nat Rev Drug Discov. 2006;5:399-410.

18. Xue YM, Deng CY, Wei W, Liu FZ, Yang H, Liu Y, et al. Macrophage migration inhibitory factor promotes cardiac fibroblast proliferation through the Src kinase signaling pathway. Mol Med Rep. 2018;17:3425-31.

19. Tynan A, Mawhinney L, Armstrong ME, O'Reilly C, Kennedy S, Caraher E, et al. Macrophage migration inhibitory factor enhances Pseudomonas aeruginosa biofilm formation, potentially contributing to cystic fibrosis pathogenesis. FASEB J. 2017;31:5102-10.

20. Leng L, Metz CN, Fang Y, Xu J, Donnelly S, Baugh J, et al. MIF signal transduction initiated by binding to CD74. J Exp Med. 2003;197:1467-76. 
21. Zhang Y, Zhou Y, Chen S, Hu Y, Zhu Z, Wang Y, et al. Macrophage migration inhibitory factor facilitates prostaglandin E2 production of astrocytes to tune inflammatory milieu following spinal cord injury. J Neuroinflammation. 2019;16:85.

22. Zhou Y, Guo W, Zhu Z, Hu Y, Wang Y, Zhang X, et al. Macrophage migration inhibitory factor facilitates production of CCL5 in astrocytes following rat spinal cord injury. J Neuroinflammation. 2018;15:253.

23. Lue H, Kapurniotu A, Fingerle-Rowson G, Roger T, Leng L, Thiele M, et al. Rapid and transient activation of the ERK MAPK signalling pathway by macrophage migration inhibitory factor (MIF) and dependence on JAB1/CSN5 and Src kinase activity. Cell Signal. 2006;18:688-703.

24. Onodera S, Suzuki K, Kaneda K, Fujinaga M, Nishihira J. Growth factor-induced expression of macrophage migration inhibitory factor in osteoblasts: relevance to the plasminogen activator system. Semin Thromb Hemost. 1999;25:563-8.

25. Chen AF, Lee YS, Seidl AJ, Abboud JA. Arthrofibrosis and large joint scarring. Connect Tissue Res. 2019;60:21-8.

26. Li D, Wang H, He JY, Wang CL, Feng WJ, Shen C, et al. Inflammatory and fibrosis infiltration in synovium associated with the progression in developmental dysplasia of the hip. Mol Med Rep. 2019;19:2808-16.

27. Kalluri R, Zeisberg M. Fibroblasts in cancer. Nat Rev Cancer. 2006;6:392-401.

28. Meneghin A, Hogaboam CM. Infectious disease, the innate immune response, and fibrosis. J Clin Invest. 2007;17:530-8.

29. Otte JM, Rosenberg IM, Podolsky DK. Intestinal myofibroblasts in innate immune responses of the intestine. Gastroenterology. 2003;124:1866-78.

30. Creagh EM, O'Neill LA. TLRs. NLRs and RLRs: a trinity of pathogen sensors that co-operate in innate immunity. Trends Immunol. 2006;27:352-7.

31. Monument MJ, Hart DA, Befus AD, Salo PT, Zhang M, Hildebrand KA. The mast cell stabilizer ketotifen reduces joint capsule fibrosis in a rabbit model of post-traumatic joint contractures. Inflamm Res. 2012;61:285-92.

32. Hagiwara Y, Chimoto E, Takahashi I, Ando A, Sasano Y, Itoi E. Expression of transforming growth factor-beta 1 and connective tissue growth factor in the capsule in a rat immobilized knee model. Ups J Med Sci. 2008;113:221-34.

33. Kaneguchi A, Ozawa J, Kawamata S, Yamaoka K. Development of arthrogenic joint contracture as a result of pathological changes in remobilized rat knees. J Orthop Res. 2017;35:1414-23.

34. Lake SP, Castile RM, Borinsky S, Dunham CL, Havlioglu N, Galatz LM. Development and use of an animal model to study post-traumatic stiffness and contracture of the elbow. J Orthop Res. 2016;34:354-64.

35. Hildebrand KA, Zhang M, Germscheid NM, Wang C, Hart DA. Cellular, matrix, and growth factor components of the joint capsule are modified early in the process of posttraumatic contracture formation in a rabbit model. Acta Orthop. 2008;79:116-25. 
36. Soppert J, Kraemer S, Beckers C, Averdunk L, Möllmann J, Denecke B, et al. Soluble CD74 Reroutes MIF/CXCR4/AKT-Mediated Survival of Cardiac Myofibroblasts to Necroptosis. J Am Heart Assoc. 2018;7:e009384.

37. Heinrichs D, Knauel M, Offermanns C, Berres ML, Nellen A, Leng L. Set al. Macrophage migration inhibitory factor (MIF) exerts antifibrotic effects in experimental liver fibrosis via CD74. Proc Natl Acad Sci U S A. 2011;108:17444-9.

38. Günther S, Bordenave J, Hua-Huy T, Nicco C, Cumont A, Thuillet R, et al. Macrophage Migration Inhibitory Factor (MIF) Inhibition in a Murine Model of Bleomycin-Induced Pulmonary Fibrosis. Int J Mol Sci. 2018;19:4105.

39. Weiskirchen R, Weiskirchen S, Tacke F. Organ and tissue fibrosis: Molecular signals, cellular mechanisms and translational implications. Mol Aspects Med. 2019;65:2-15.

40. Sun Y, Liu WZ, Liu T, Feng X, Yang N, Zhou HF. Signaling pathway of MAPK/ERK in cell proliferation, differentiation, migration, senescence and apoptosis. J Recept Signal Transduct Res. 2015;35:6004.

41. An N, Peng J, He G, Fan X, Li F, Chen H. Involvement of Activation of Mitogen-Activated Protein Kinase (MAPK)/Extracellular Signal-Regulated Kinase (ERK) Signaling Pathway in Proliferation of Urethral Plate Fibroblasts in Finasteride-Induced Rat Hypospadias. Med Sci Monit. 2018;24:8984-92.

42. Khalil N, Xu YD, O'Connor R, Duronio V. Proliferation of pulmonary interstitial fibroblasts is mediated by transforming growth factor-beta1-induced release of extracellular fibroblast growth factor-2 and phosphorylation of p38 MAPK and JNK. J Biol Chem. 2005;280:43000-9.

43. Gabbiani G. The myofibroblast in wound healing and fibrocontractive diseases. J Pathol. 2003;200:500-3.

44. Vaughan MB, Howard EW, Tomasek JJ. Transforming growth factor-beta1 promotes the morphological and functional differentiation of the myofibroblast. Exp Cell Res. 2000;257:180-9.

45. Li F, Liu S, Fan C. Lentivirus-mediated ERK2 siRNA reduces joint capsule fibrosis in a rat model of post-traumatic joint contracture. Int J Mol Sci. 2013;14:20833-44.

46. Trudel G, Uhthoff HK. Contractures secondary to immobility: is the restriction articular or muscular? An experimental longitudinal study in the rat knee. Arch Phys Med Rehabil. 2000;81:6-13.

47. Buss DG, Giuliano EA, Sharma A, Mohan RR. Isolation and cultivation of equine corneal keratocytes, fibroblasts and myofibroblasts. Vet Ophthalmol. 2010;13:37-42.

\section{Figures}


$\mathbf{a}$
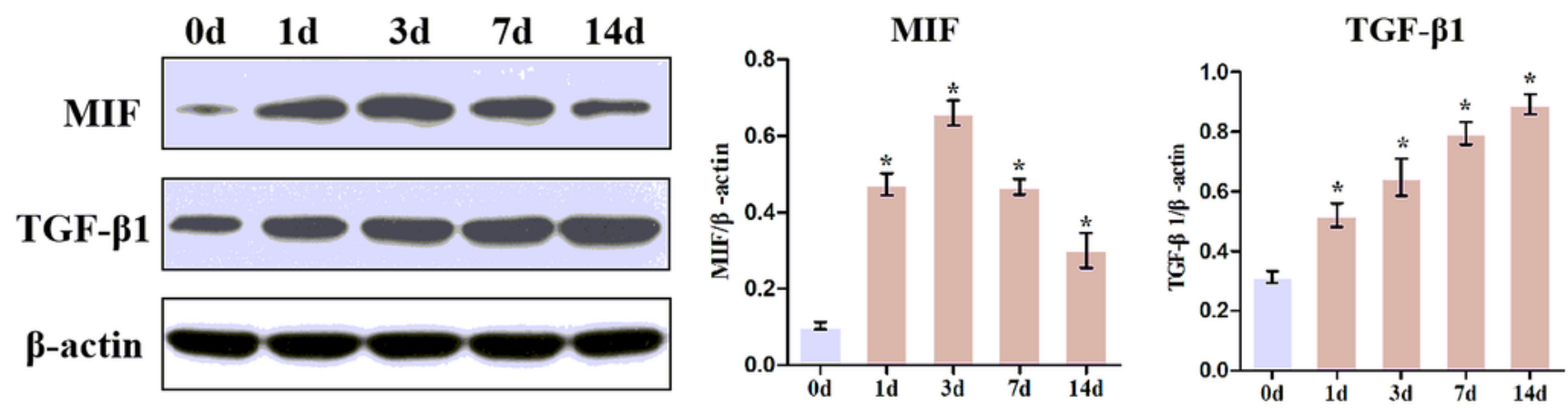
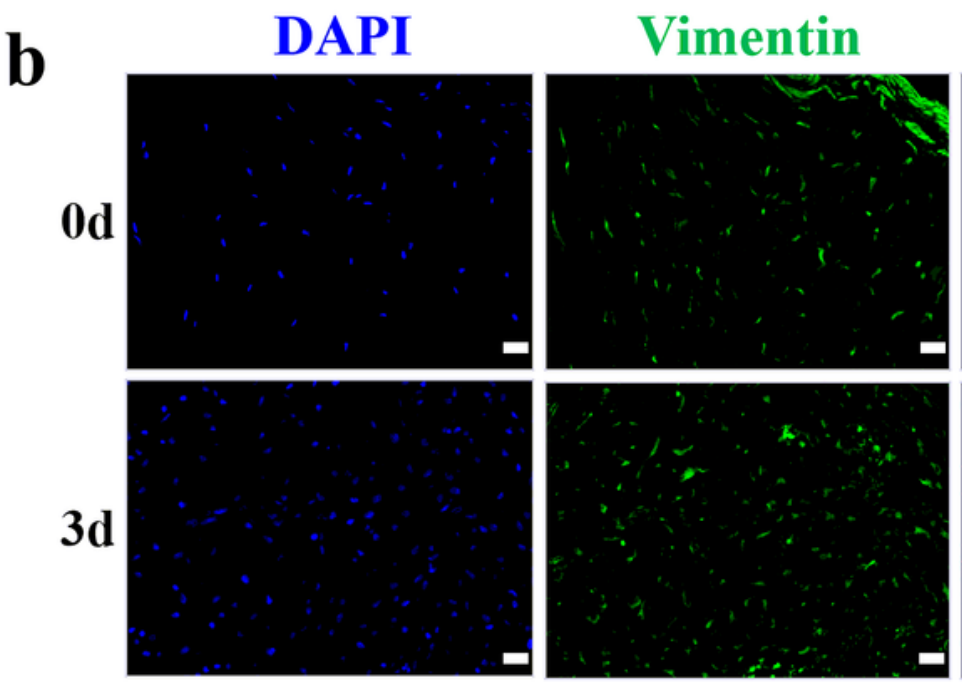

$3 d$

c

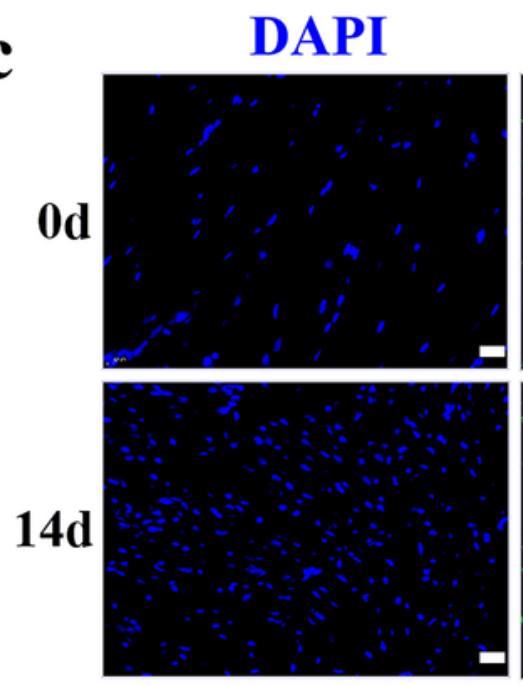

Vimentin

MIF
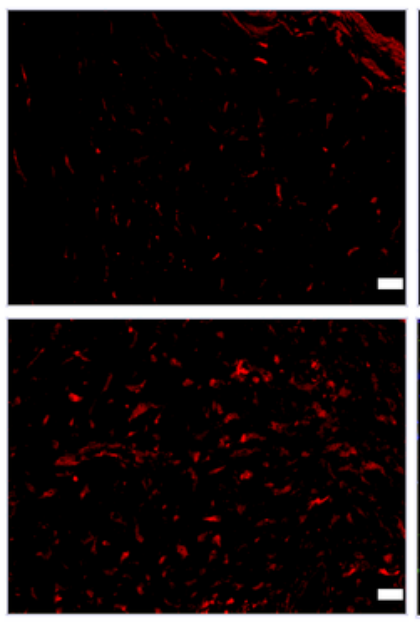

Vimentin
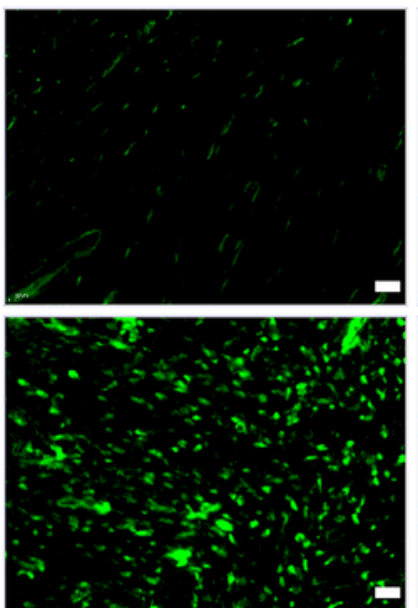

TGF- $\beta 1$
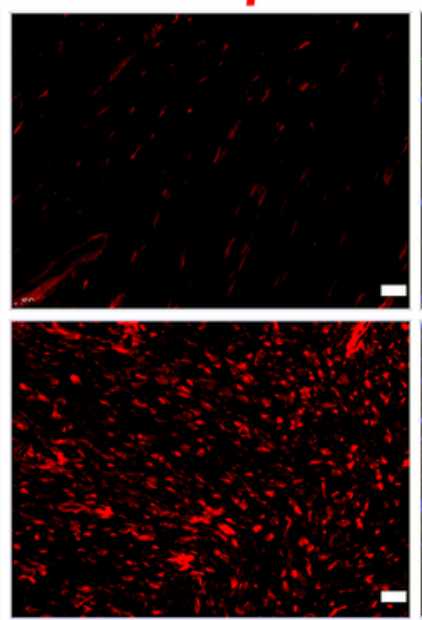

Merge
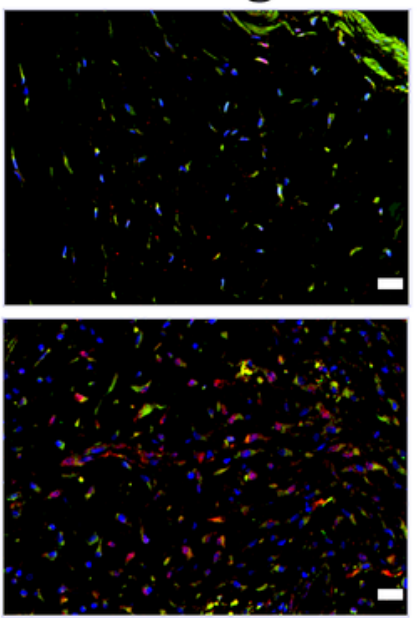

Merge

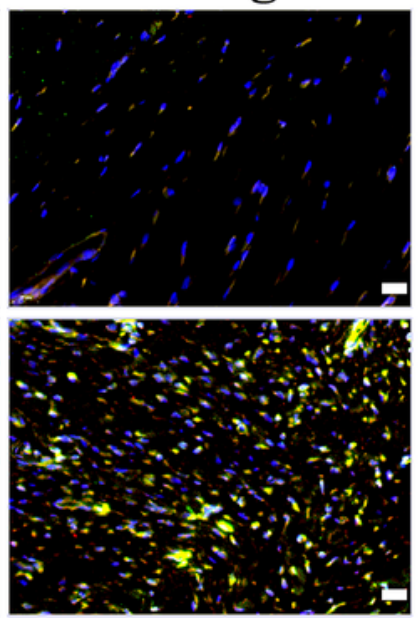

Figure 1

MIF and TGF- $\beta 1$ expression increased in the posterior joint capsule after PTJC. a Western blot analysis of MIF and TGF- $\beta 1$ protein levels in posterior joint capsule following PTJC at 0, 1, 3, 7, and 14 days, respectively. Quantities were normalized to endogenous $\beta$-actin. b Immunostaining showed colocalization of MIF (red) with fibroblasts in injured posterior joint capsule at 0 and 3 days after PTJC. Cell nucleus were stained with DAPI (blue). Vimentin was used as the marker of fibroblasts (green). c Immunostaining 
showed colocalization of TGF- $\beta 1$ (red) with fibroblasts in posterior joint capsule at 0 and 14 days after PTJC. Scale bars, $20 \mu \mathrm{m}$. All experiments were conducted independently at least three times. Error bars represent standard deviation. ${ }^{*} \mathrm{P}<0.05$ compared with $0 \mathrm{~d}$ group.

$\mathbf{a}$
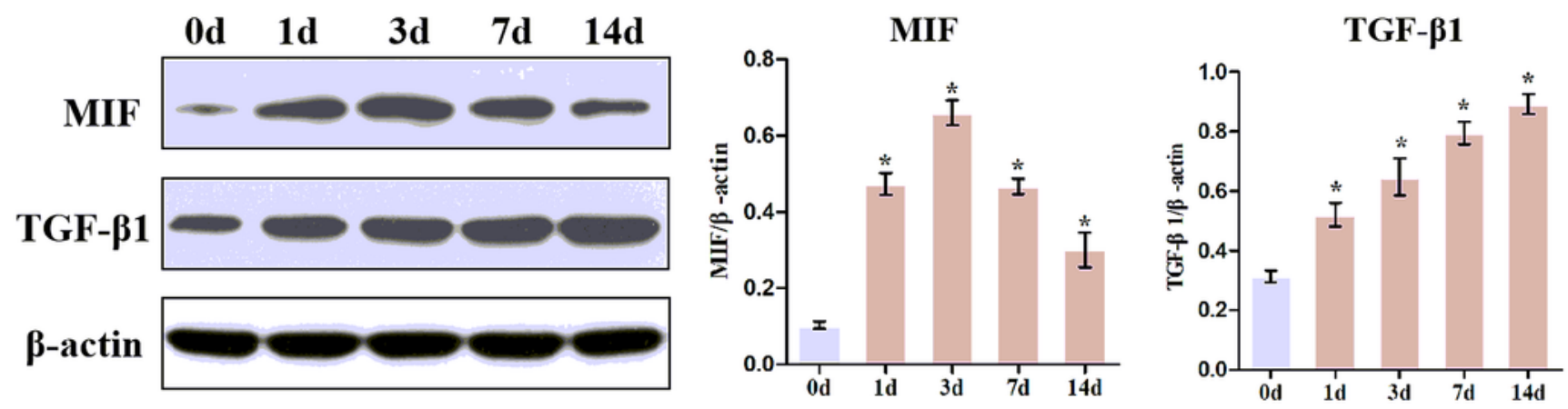

b
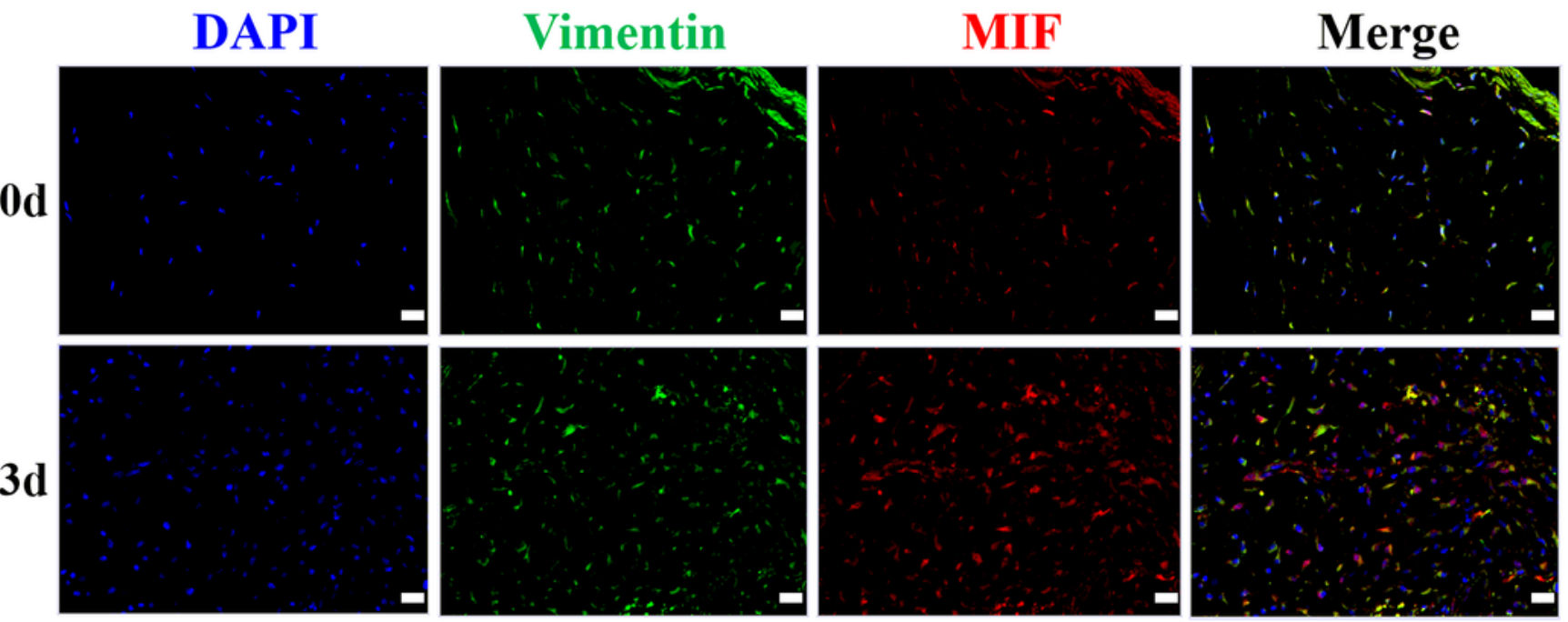

c

DAPI
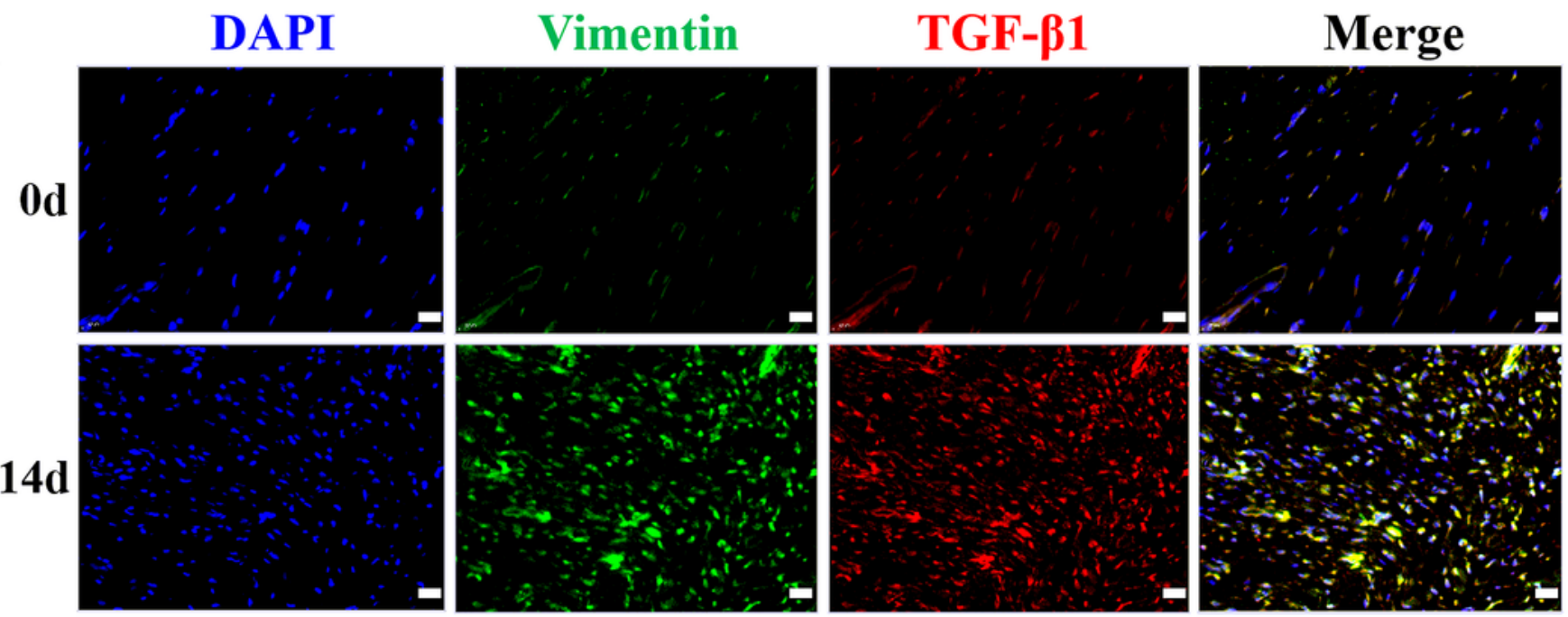

Figure 1

MIF and TGF- $\beta 1$ expression increased in the posterior joint capsule after PTJC. a Western blot analysis of MIF and TGF- $\beta 1$ protein levels in posterior joint capsule following PTJC at 0, 1, 3, 7, and 14 days, 
respectively. Quantities were normalized to endogenous $\beta$-actin. b Immunostaining showed colocalization of MIF (red) with fibroblasts in injured posterior joint capsule at 0 and 3 days after PTJC. Cell nucleus were stained with DAPI (blue). Vimentin was used as the marker of fibroblasts (green). c Immunostaining showed colocalization of TGF- $\beta 1$ (red) with fibroblasts in posterior joint capsule at 0 and 14 days after PTJC. Scale bars, $20 \mu \mathrm{m}$. All experiments were conducted independently at least three times. Error bars represent standard deviation. ${ }^{*} \mathrm{P}<0.05$ compared with 0 d group.
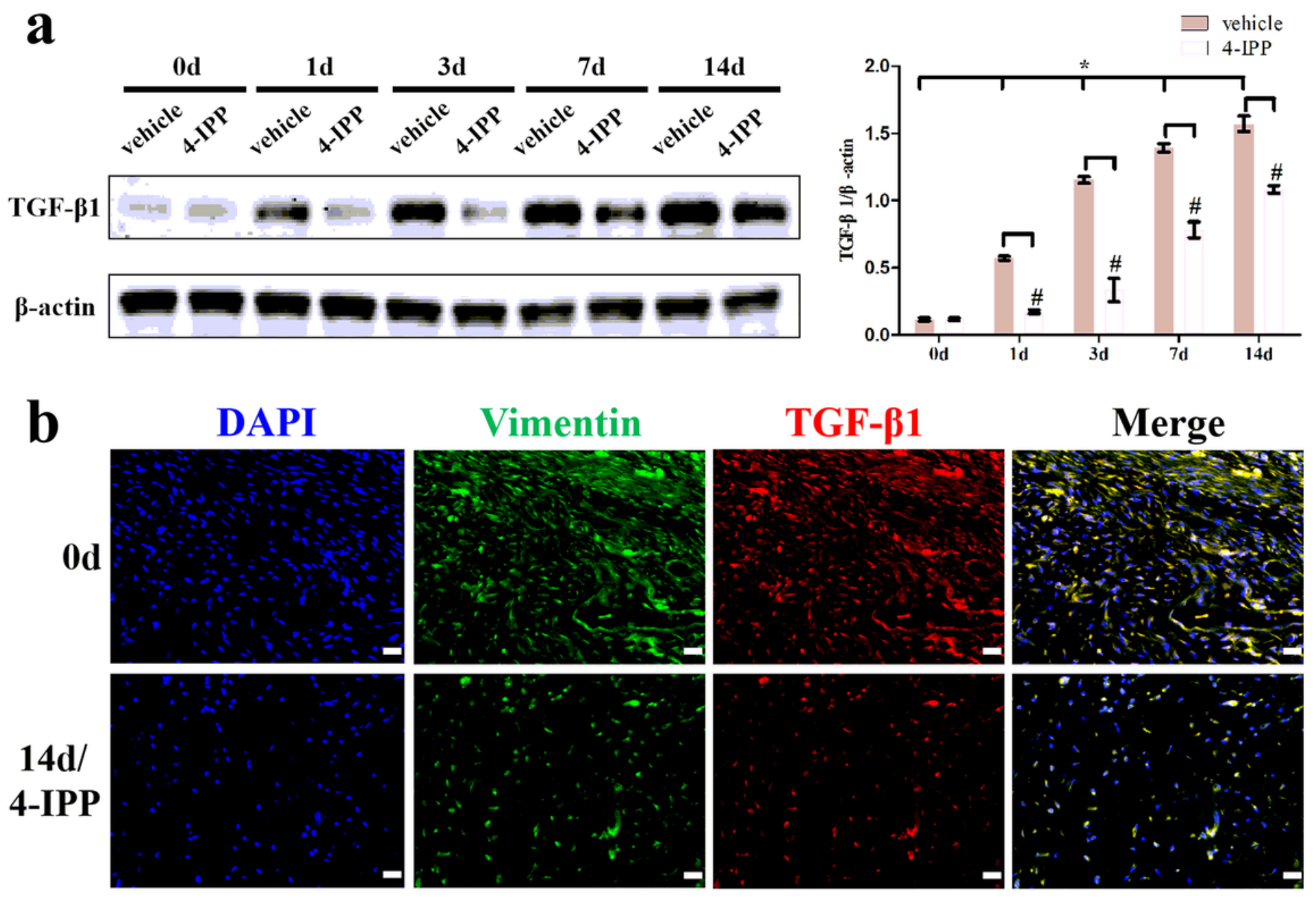

Figure 2

Inhibition of MIF in the lesion area attenuated TGF- $\beta 1$ expression. a Western blot analysis of TGF- $\beta 1$ protein levels for the injured posterior joint capsule at different time points with or without injection of 10 $\mu \mathrm{L}$ 4-IPP $(100 \mathrm{mM})$ at the lesion area by western blot. b Immunostaining of TGF- $\beta 1$ (red) in the injured posterior joint capsule at 0 and 14 days, with or without injection of 4-IPP, respectively. Scale bar, $20 \mu \mathrm{m}$. All experiments were conducted independently at least three times. Error bars represent standard deviation. ${ }^{*} \mathrm{P}<0.05$ compared with $0 \mathrm{~d}$ group. \#P $<0.05$ compared with vehicle group. 

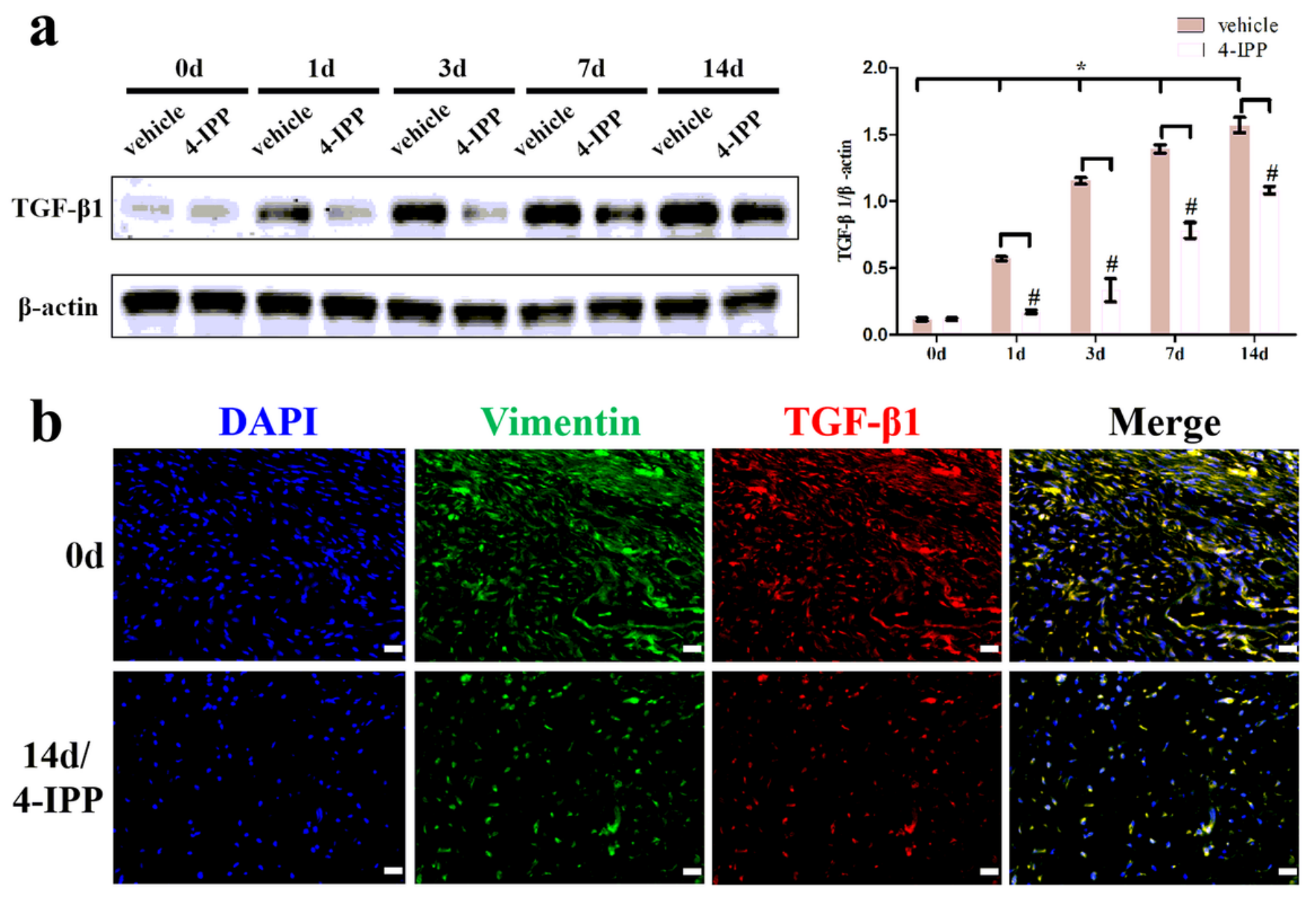

Figure 2

Inhibition of MIF in the lesion area attenuated TGF- $\beta 1$ expression. a Western blot analysis of TGF- $\beta 1$ protein levels for the injured posterior joint capsule at different time points with or without injection of 10 $\mu \mathrm{L}$ 4-IPP $(100 \mathrm{mM})$ at the lesion area by western blot. b Immunostaining of TGF- $\beta 1$ (red) in the injured posterior joint capsule at 0 and 14 days, with or without injection of 4-IPP, respectively. Scale bar, $20 \mu \mathrm{m}$. All experiments were conducted independently at least three times. Error bars represent standard deviation. ${ }^{*} \mathrm{P}<0.05$ compared with $0 \mathrm{~d}$ group. \#P $<0.05$ compared with vehicle group. 
$\mathbf{a}$
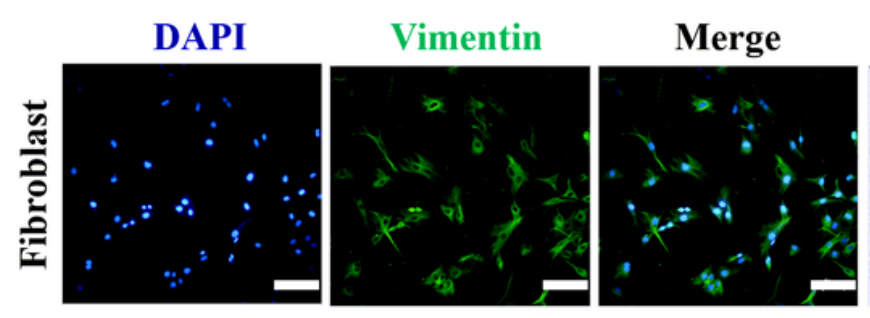

BF
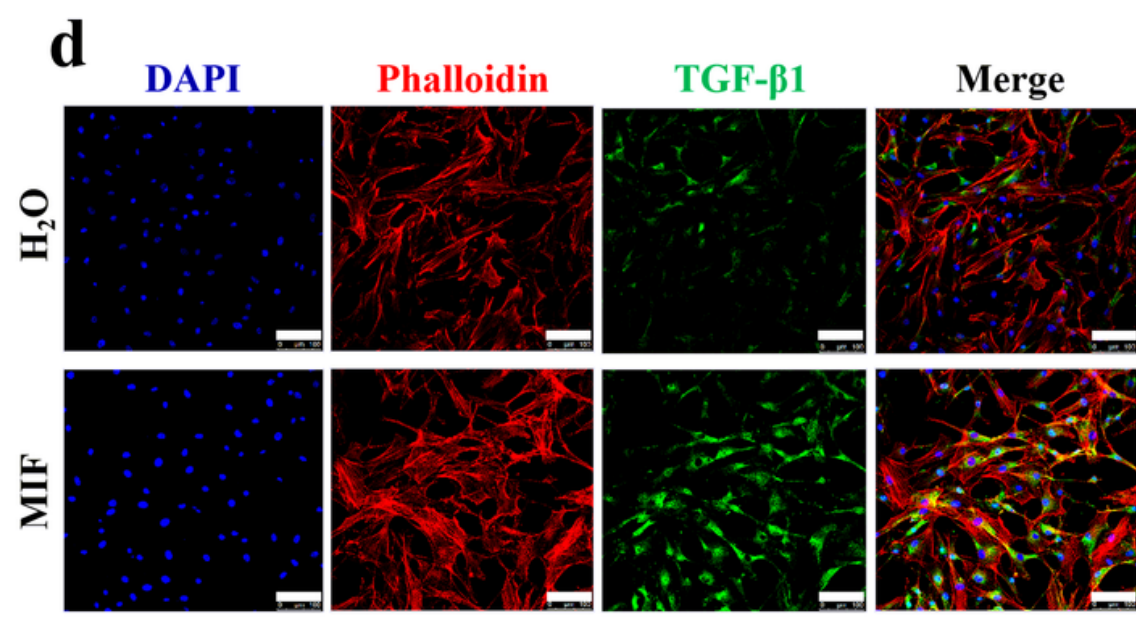

b
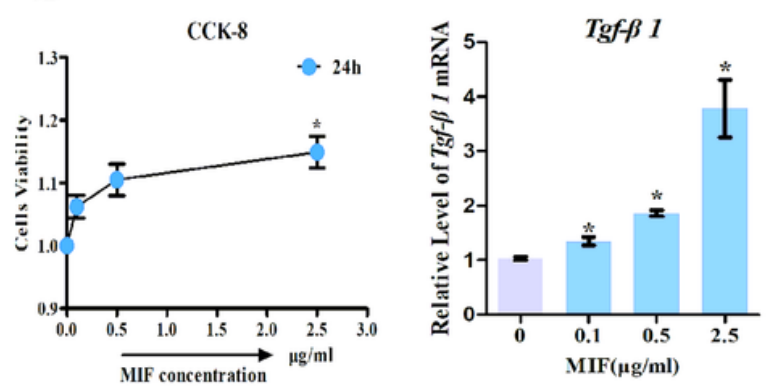

$\mathbf{e}$
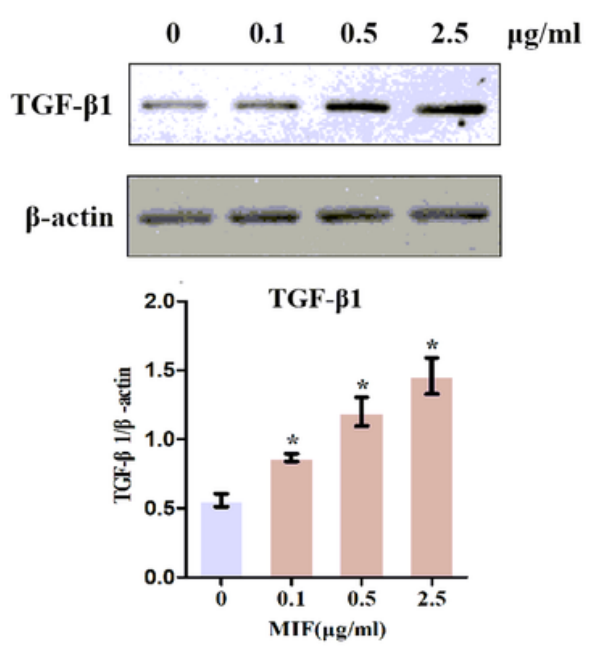

Figure 3

Determination of TGF- $\beta 1$ expression in response to MIF stimulation. a Isolated primary joint capsule fibroblasts stained with vimentin (green), DAPI (blue), and displayed in classical microscopy image (BF). b CCK-8 assay was performed on joint capsule fibroblasts treated with varying MIF concentrations. c-e Expression of TGF- $\beta 1$ were assessed by qRT-PCR (c), immunofluorescence (d, Phalloidin was used as cytoskeleton (red)), and western blot (e) following joint capsule fibroblasts treatment with $0-2.5 \mu \mathrm{g} / \mathrm{mL}$ recombinant MIF for $24 \mathrm{~h}$. Scale bar, $100 \mu \mathrm{m}$. All experiments were conducted independently at least three times. Error bars represent standard deviation. ${ }^{*} \mathrm{P}<0.05$ compared with $0 \mu \mathrm{g} / \mathrm{mL}$ group. 
$\mathbf{a}$
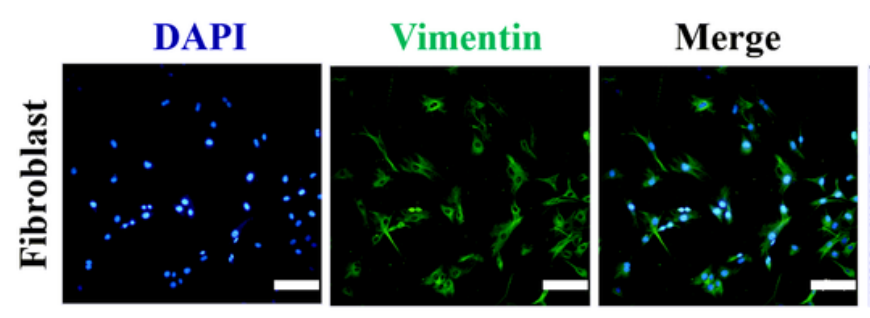

BF
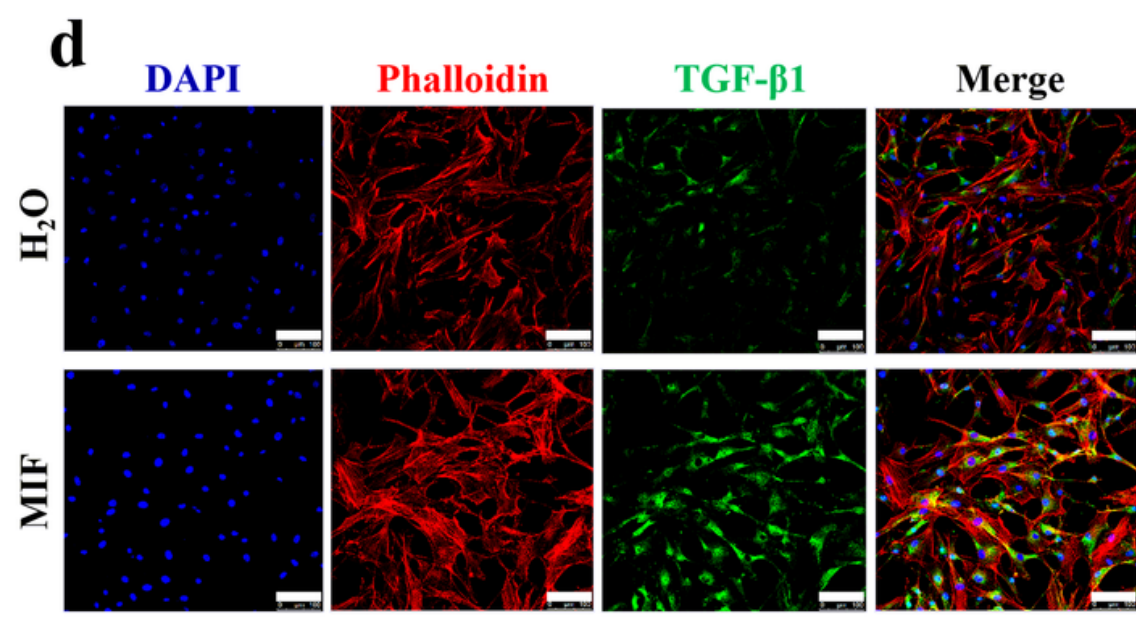

b
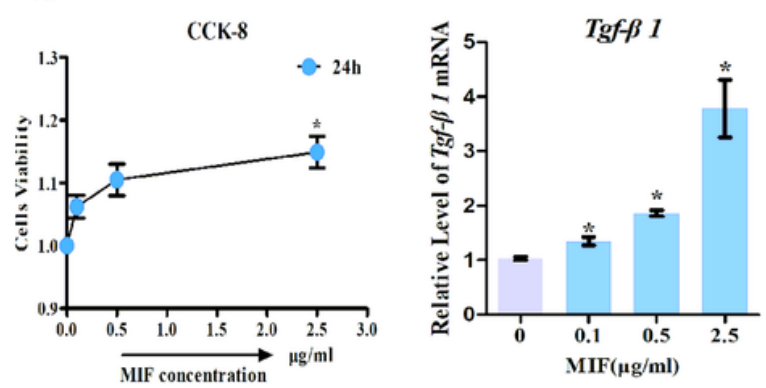

$\mathbf{e}$
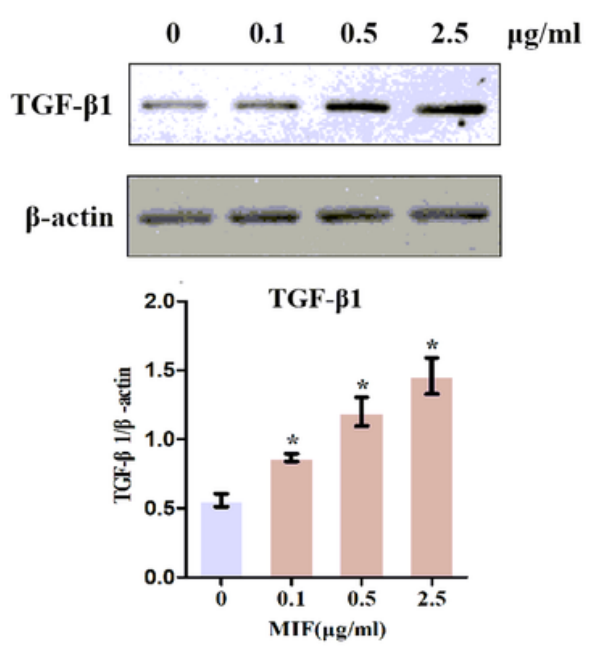

Figure 3

Determination of TGF- $\beta 1$ expression in response to MIF stimulation. a Isolated primary joint capsule fibroblasts stained with vimentin (green), DAPI (blue), and displayed in classical microscopy image (BF). b CCK-8 assay was performed on joint capsule fibroblasts treated with varying MIF concentrations. c-e Expression of TGF- $\beta 1$ were assessed by qRT-PCR (c), immunofluorescence (d, Phalloidin was used as cytoskeleton (red)), and western blot (e) following joint capsule fibroblasts treatment with $0-2.5 \mu \mathrm{g} / \mathrm{mL}$ recombinant MIF for $24 \mathrm{~h}$. Scale bar, $100 \mu \mathrm{m}$. All experiments were conducted independently at least three times. Error bars represent standard deviation. ${ }^{*} \mathrm{P}<0.05$ compared with $0 \mu \mathrm{g} / \mathrm{mL}$ group. 
a

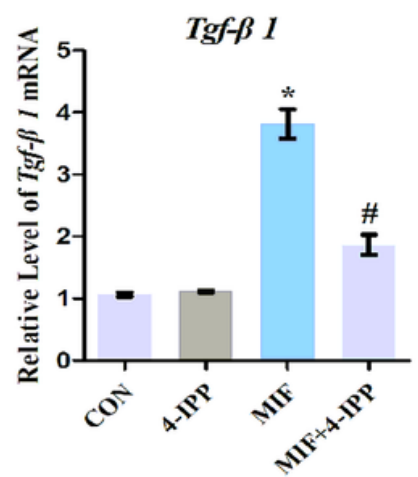

c DAPI
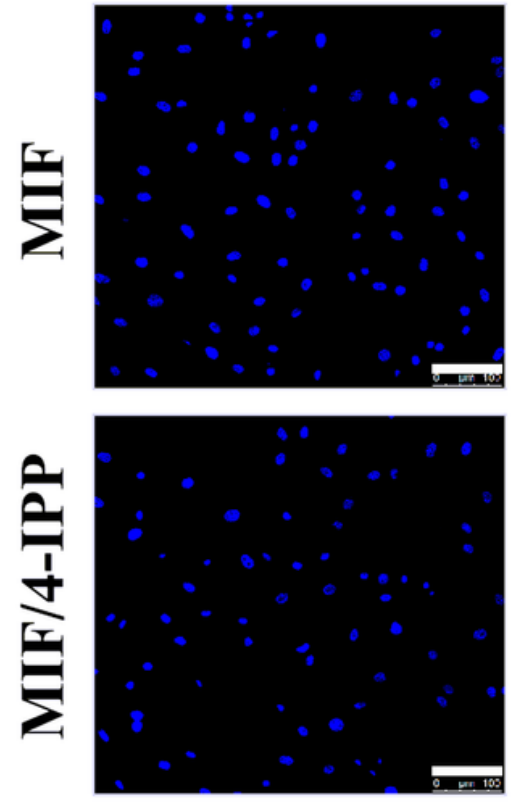

b

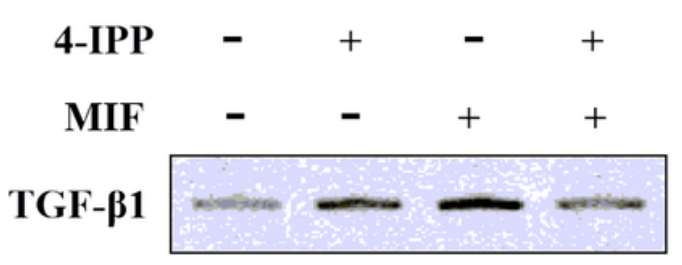

$\beta$-actin

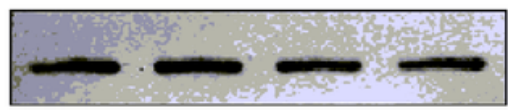

TGF- $\beta 1$

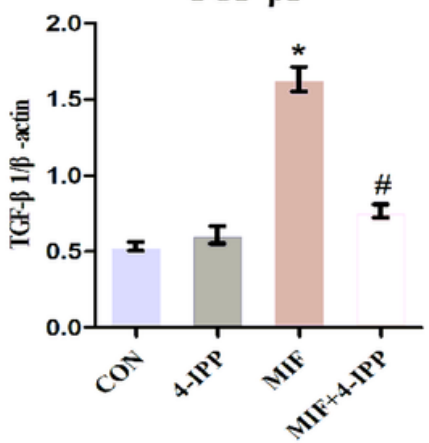

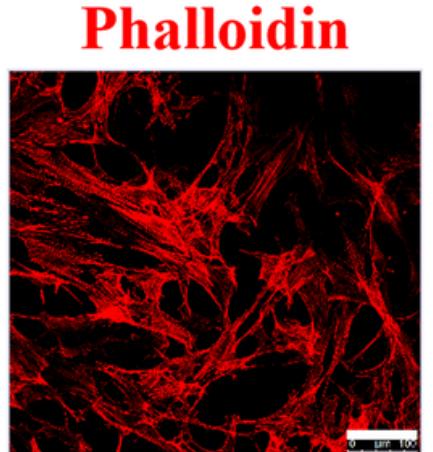
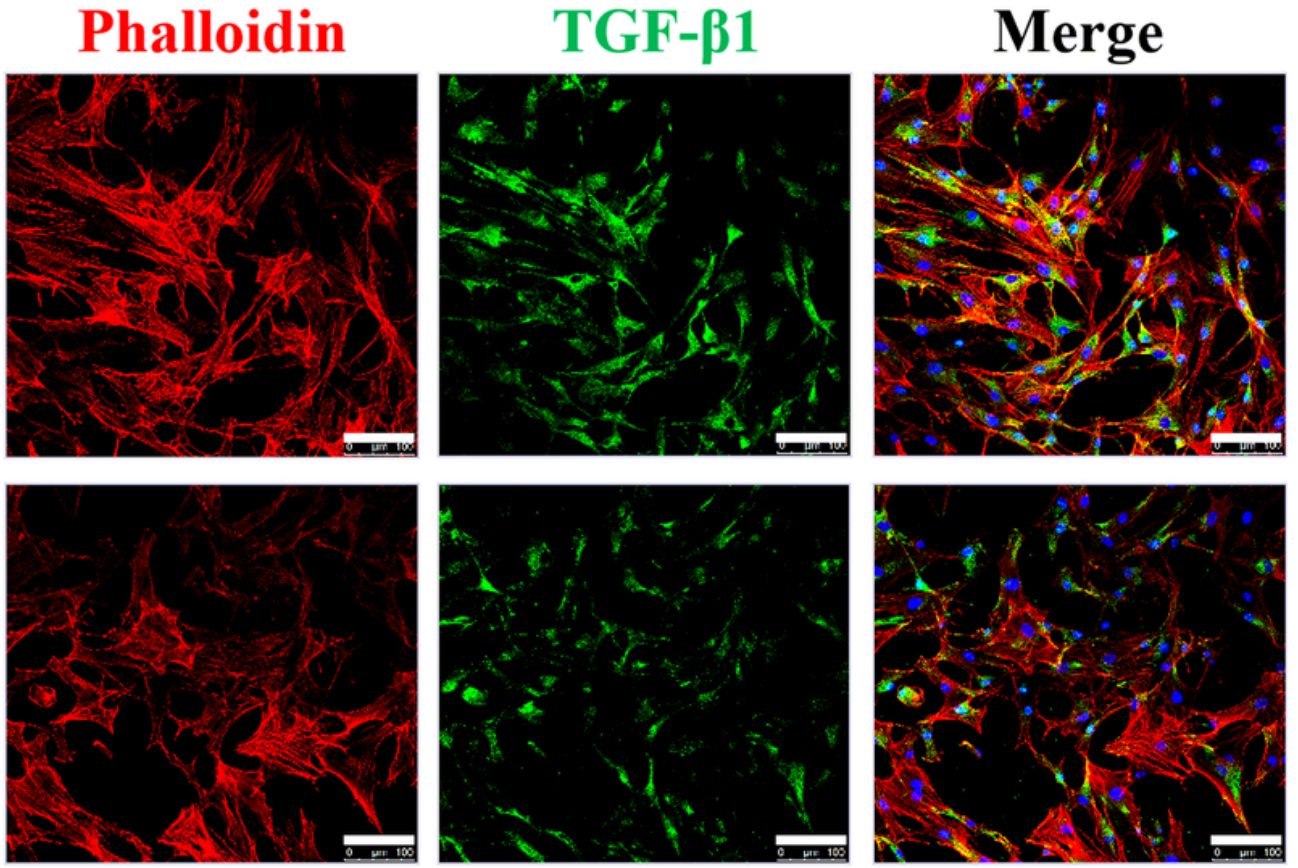

Figure 4

Effects of MIF inhibitor 4-IPP on the expression of TGF- $\beta 1$. a-c Expression of TGF- $\beta 1$ in joint capsule fibroblasts in response to $2 \mu \mathrm{g} / \mathrm{mL}$ recombinant MIF combined with $50 \mu \mathrm{M}$ 4-IPP treatment for $24 \mathrm{~h}$ was determined by qRT-PCR (a), western blot (b), and immunofluorescence (c). Scale bar, $100 \mu \mathrm{m}$. All experiments were conducted independently at least three times. Error bars represent standard deviation. *P $<0.05$ compared with CON group. \#P $<0.05$ compared with MIF group. 
a

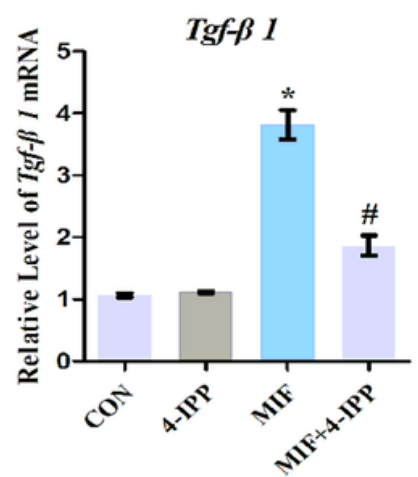

c
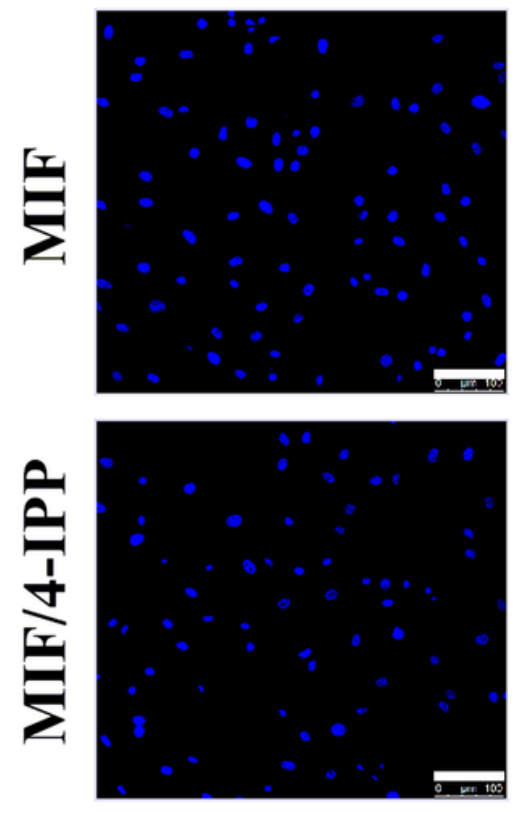

DAPI b

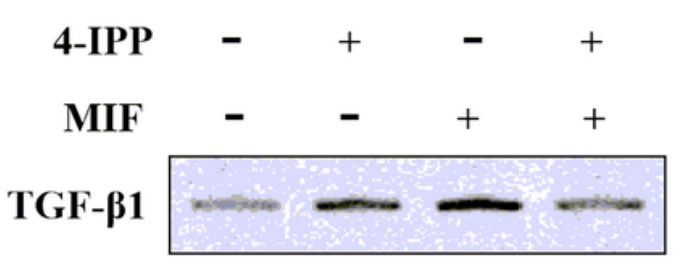

$\boldsymbol{\beta}$-actin

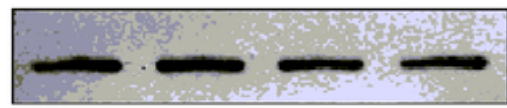

TGF- $\beta 1$

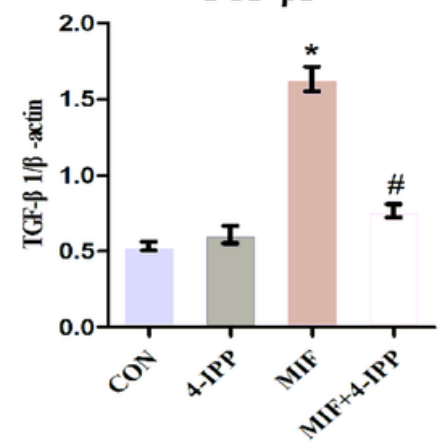

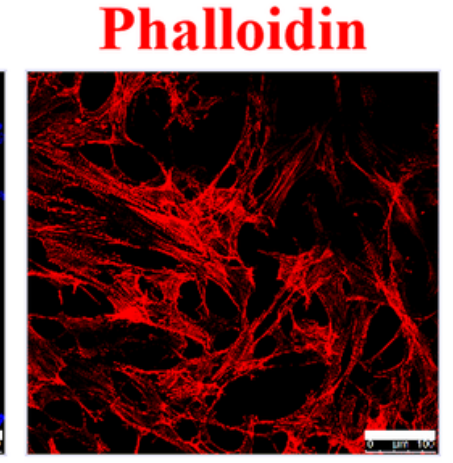

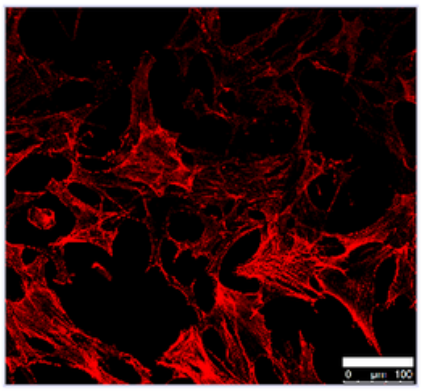

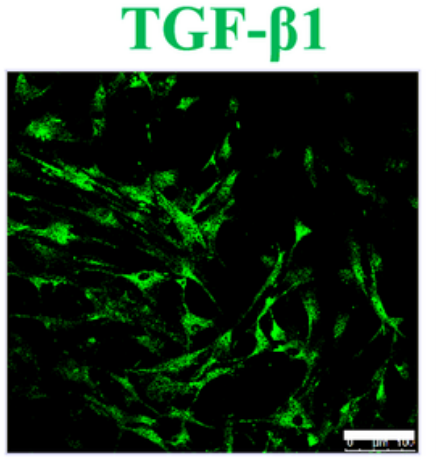
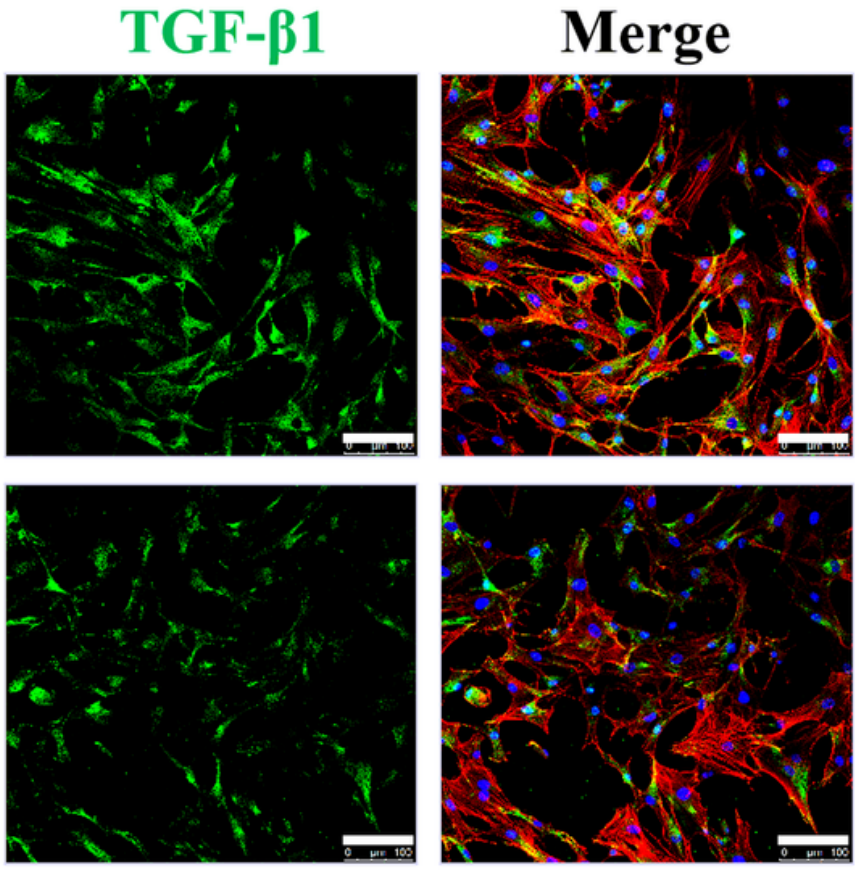

Figure 4

Effects of MIF inhibitor 4-IPP on the expression of TGF- $\beta 1$. a-c Expression of TGF- $\beta 1$ in joint capsule fibroblasts in response to $2 \mu \mathrm{g} / \mathrm{mL}$ recombinant MIF combined with $50 \mu \mathrm{M}$ 4-IPP treatment for $24 \mathrm{~h}$ was determined by qRT-PCR (a), western blot (b), and immunofluorescence (c). Scale bar, $100 \mu \mathrm{m}$. All experiments were conducted independently at least three times. Error bars represent standard deviation. ${ }^{*} \mathrm{P}<0.05$ compared with CON group. \#P $<0.05$ compared with MIF group. 
$\mathbf{a}$

\section{$\frac{\text { IP }}{\text { IgG }}$ Input $\frac{\text { IP }}{\text { MIF }}$}

CD74

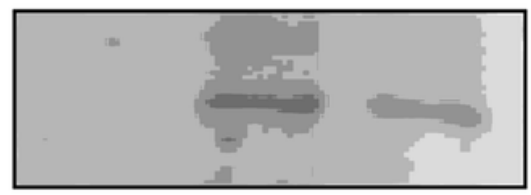

$\frac{\text { IP }}{\text { IgG }}$ Input $\frac{\text { IP }}{\text { CD74 }}$

MIF

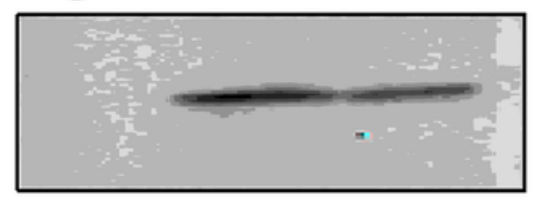

c

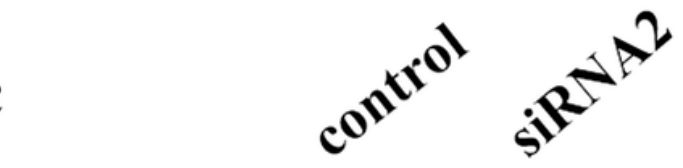

TGF- $\beta 1$

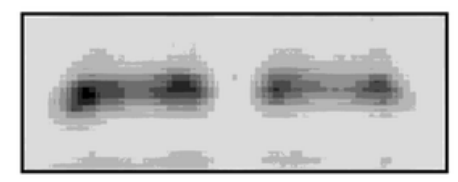

$\beta$-actin

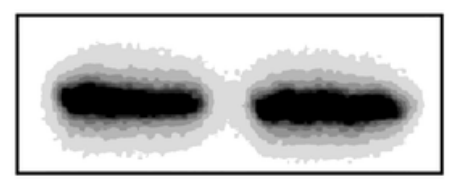

b
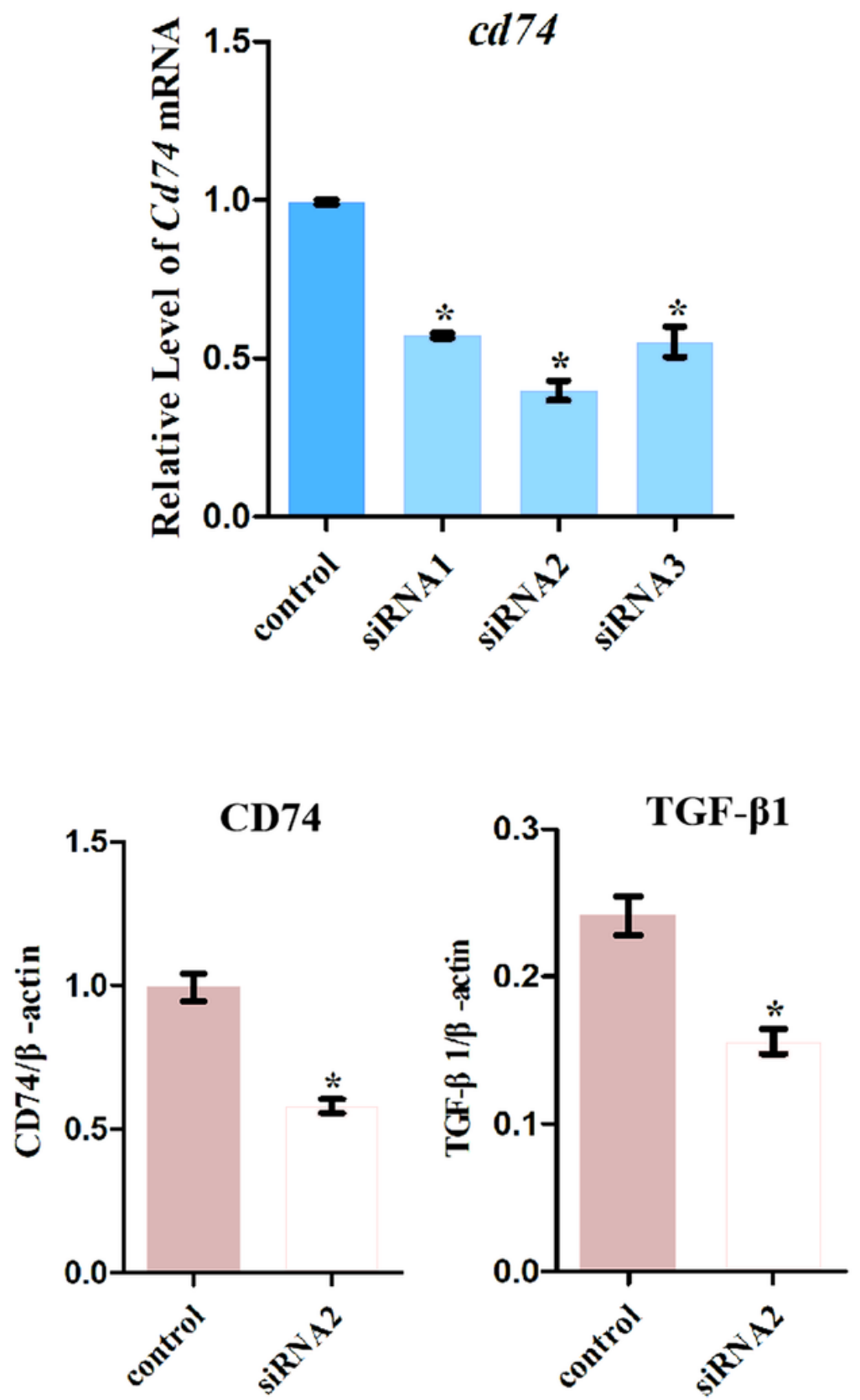

Figure 5

Effects of CD74 knockdown on the MIF-induced TGF- $\beta 1$ expression. a Immunoprecipitation determined the interaction of MIF with CD74 receptor in joint capsule fibroblasts. b Knockdown efficiency of CD74 siRNA were tested by qRT-PCR, and siRNA2 was chosen for the subsequent experiments. c Western blot analysis of CD74 and TGF- 31 expression following siRNA2 knockdown of CD74 receptor for $48 \mathrm{~h}$, and then treated with $2 \mu \mathrm{g} / \mathrm{ml}$ recombinant MIF for $24 \mathrm{~h}$. A siRNA (control) with the same nucleotide composition as siRNA2 but lacking sequence homology to the CD74 was also designed as negative 
control. All experiments were conducted independently at least three times. Error bars represent standard deviation. ${ }^{*} \mathrm{P}<0.05$ compared with control group.

$\mathbf{a}$

$$
\frac{\text { IP }}{\text { IgG }} \text { Input } \frac{\text { IP }}{\text { MIF }}
$$

CD74

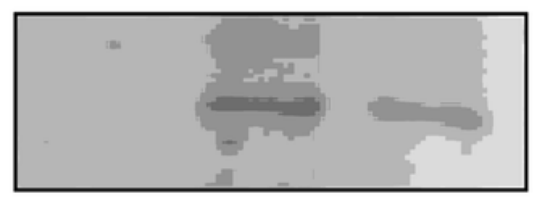

MIF

$$
\frac{I P}{\text { IgG }} \text { Input } \frac{\text { IP }}{\text { CD74 }}
$$

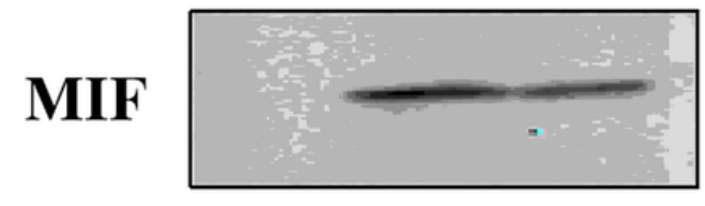

b
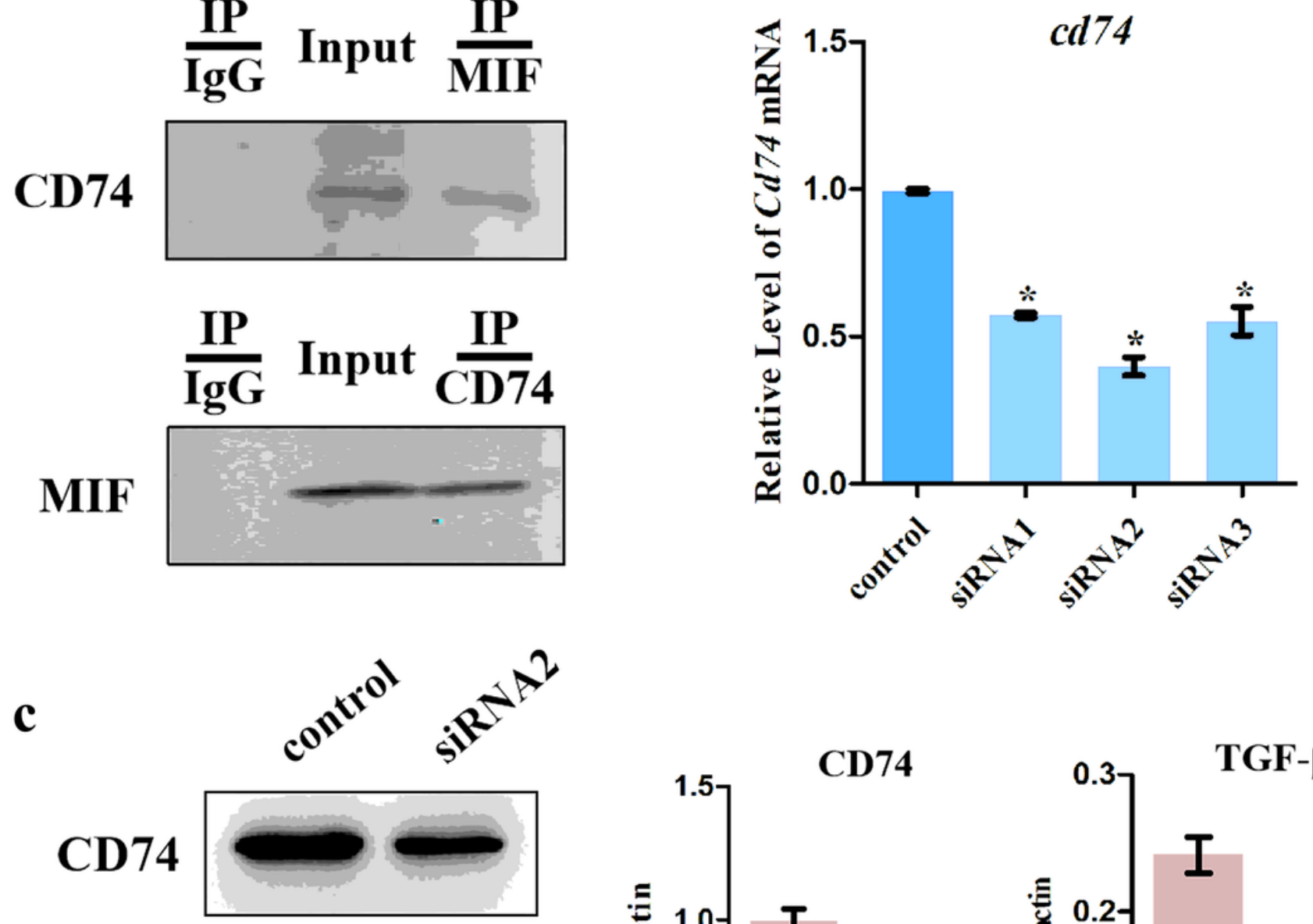

TGF- $\beta 1$

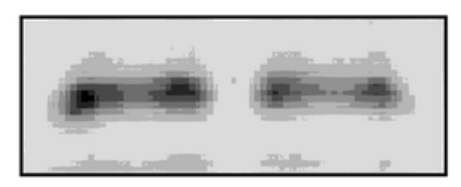

$\beta$-actin

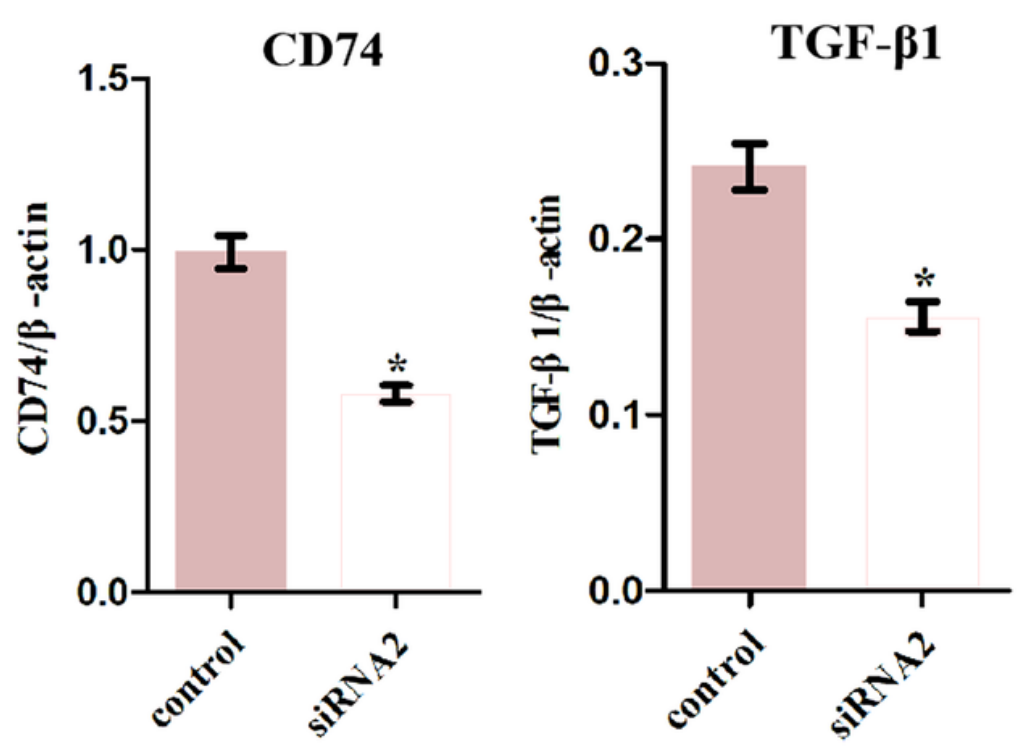

Figure 5

Effects of CD74 knockdown on the MIF-induced TGF- $\beta 1$ expression. a Immunoprecipitation determined the interaction of MIF with CD74 receptor in joint capsule fibroblasts. b Knockdown efficiency of CD74 siRNA were tested by qRT-PCR, and siRNA2 was chosen for the subsequent experiments. $c$ Western blot analysis of CD74 and TGF- 31 expression following siRNA2 knockdown of CD74 receptor for $48 \mathrm{~h}$, and then treated with $2 \mu \mathrm{g} / \mathrm{ml}$ recombinant MIF for $24 \mathrm{~h}$. A siRNA (control) with the same nucleotide 
composition as siRNA2 but lacking sequence homology to the CD74 was also designed as negative control. All experiments were conducted independently at least three times. Error bars represent standard deviation. *P $<0.05$ compared with control group.
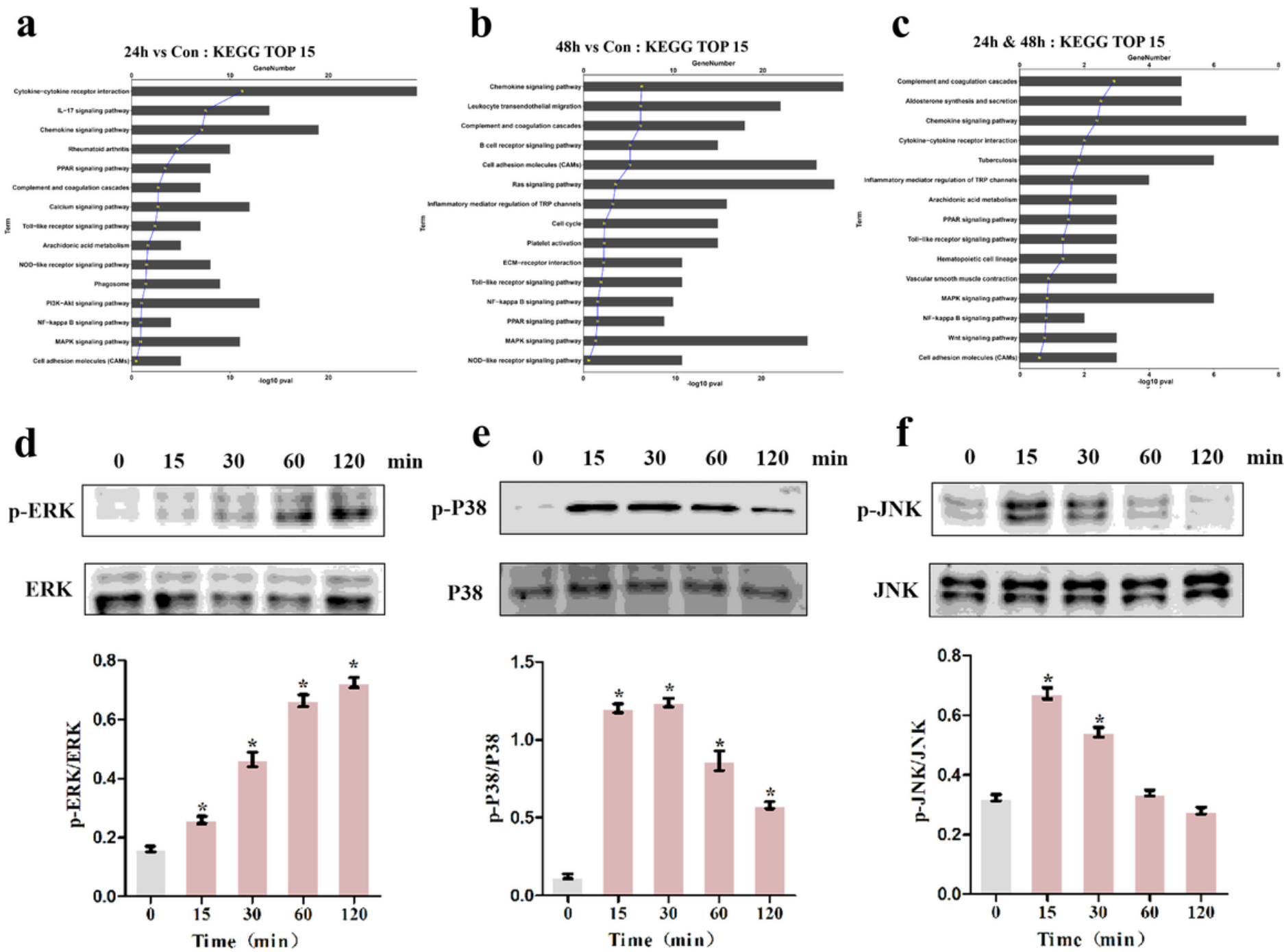

\section{Figure 6}

Effects of MIF on the activation of intracellular signaling in joint capsule fibroblasts. a, b Top 15 most significantly enriched groups for the DEGs related to pathways following treatment with $2 \mu \mathrm{g} / \mathrm{mL}$ recombinant MIF for $24 \mathrm{~h}$ (a) or $48 \mathrm{~h}$ (b). c Top 15 most significantly enriched groups for integrated DEGs (24 h \& $48 \mathrm{~h}$ ) related to pathways. d-f Western blot analysis of MAPK signaling-related proteins p-ERK(d), p-P38(e), and p-JNK(f) after joint capsule fibroblasts treated with $2 \mu \mathrm{g} / \mathrm{mL}$ recombinant MIF for 0, 15, 30, 60 , and 120 min, respectively. All experiments were conducted independently at least three times. Error bars represent standard deviation. ${ }^{*} \mathrm{P}<0.05$ compared with 0 min group. 

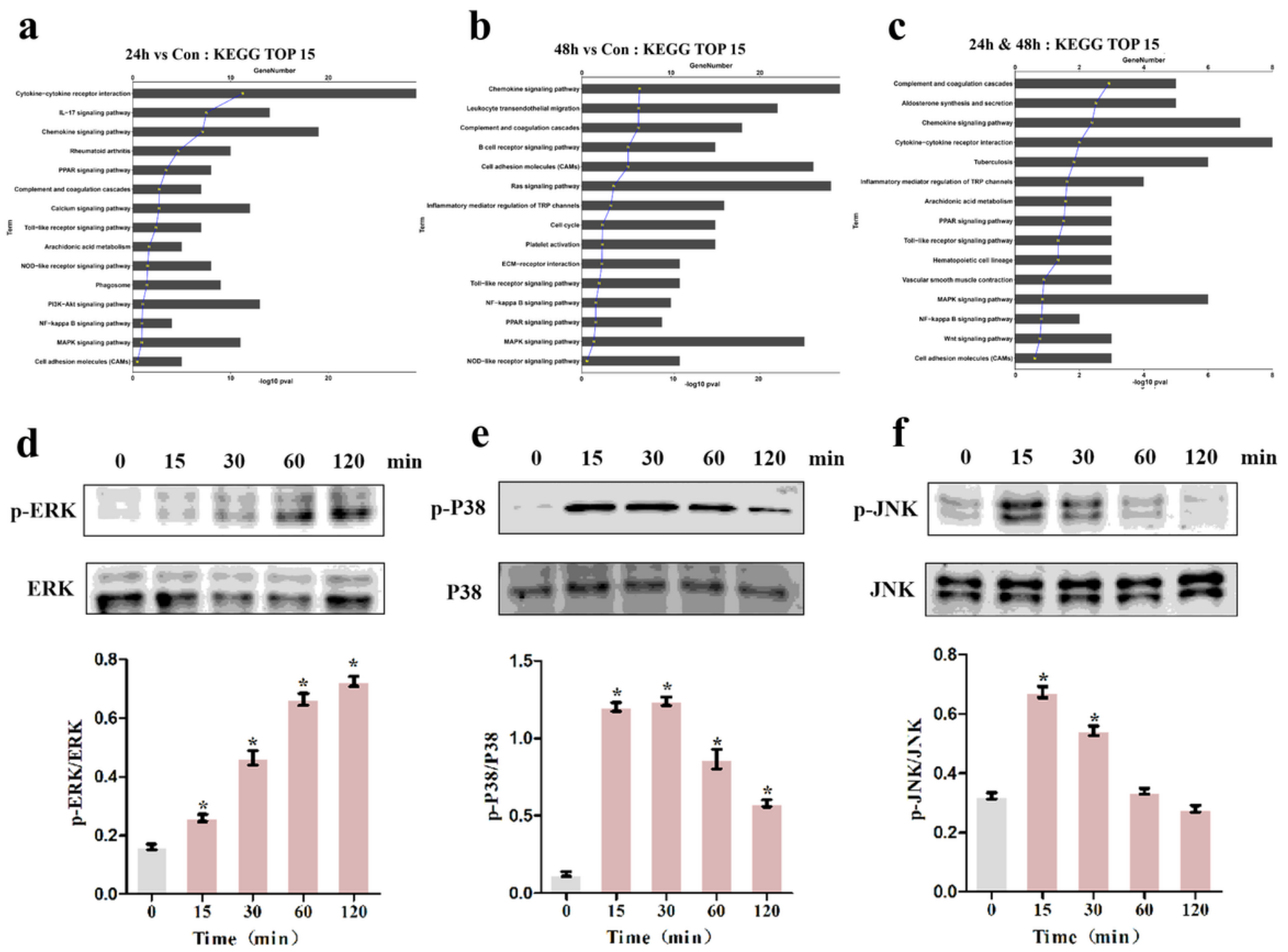

\section{Figure 6}

Effects of MIF on the activation of intracellular signaling in joint capsule fibroblasts. a, b Top 15 most significantly enriched groups for the DEGs related to pathways following treatment with $2 \mu \mathrm{g} / \mathrm{mL}$ recombinant MIF for $24 \mathrm{~h}$ (a) or $48 \mathrm{~h}$ (b). c Top 15 most significantly enriched groups for integrated DEGs $(24 \mathrm{~h} \& 48 \mathrm{~h}$ ) related to pathways. d-f Western blot analysis of MAPK signaling-related proteins $\mathrm{p}$-ERK(d), p-P38(e), and p-JNK(f) after joint capsule fibroblasts treated with $2 \mu \mathrm{g} / \mathrm{mL}$ recombinant MIF for $0,15,30$, 60 , and 120 min, respectively. All experiments were conducted independently at least three times. Error bars represent standard deviation. ${ }^{*} \mathrm{P}<0.05$ compared with 0 min group. 

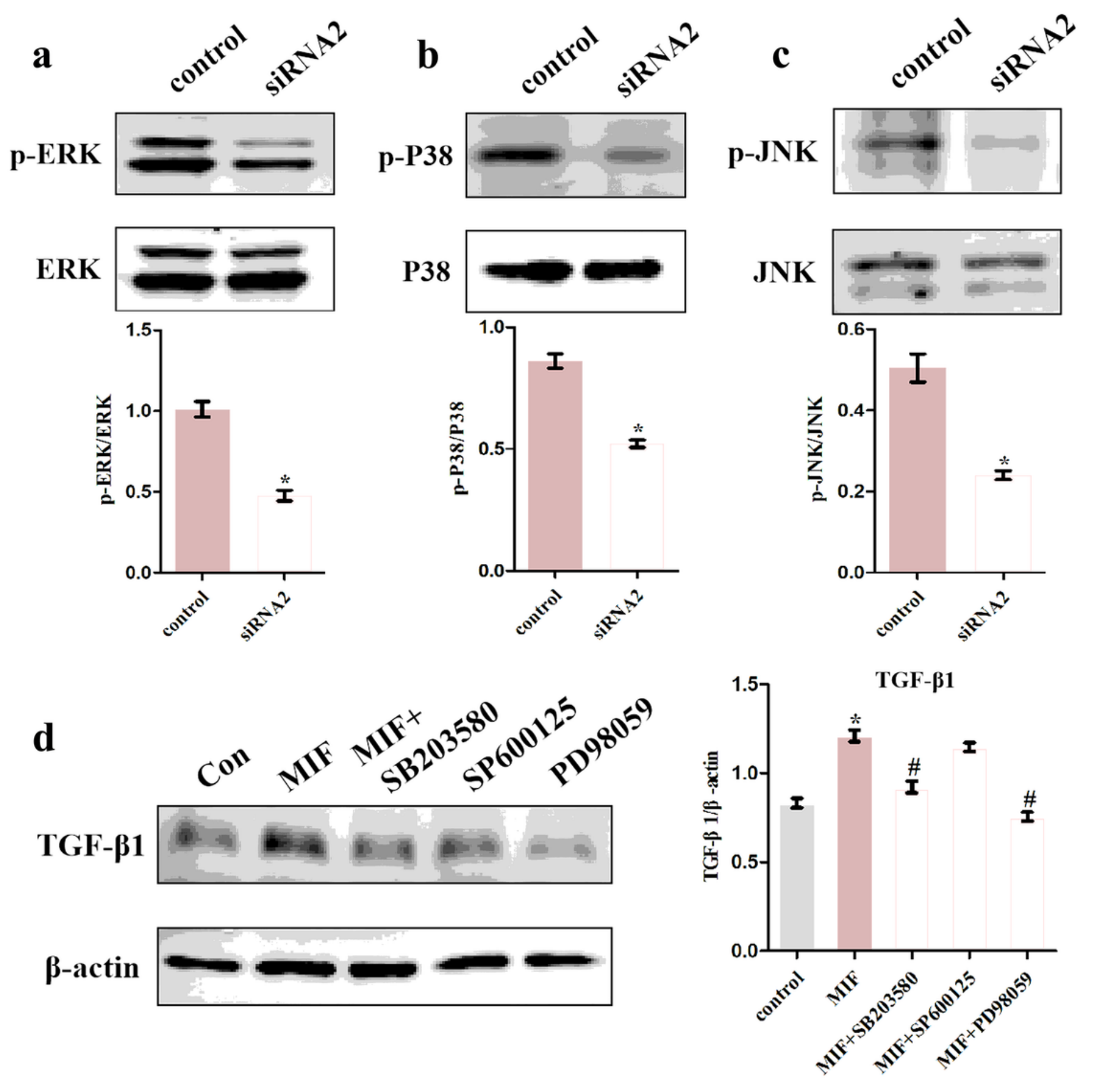

Figure 7

Determination of intracellular signaling associated with regulation of TGF- $\beta 1$ expression. a-c Western blot analysis of p-ERK(a), p-P38(b), and p-JNK(c) following joint capsule fibroblasts treated with siRNA2 or control siRNA for $48 \mathrm{~h}$ and then with $2 \mu \mathrm{g} / \mathrm{mL}$ recombinant MIF for $30 \mathrm{~min}$. $\mathrm{d}$ Joint capsule fibroblasts were pretreated with $10 \mu \mathrm{M}$ inhibitor of P38 (SB203580), JNK (SP600125), or ERK (PD98059) for $1 \mathrm{~h}$ before treatment with $2 \mu \mathrm{g} / \mathrm{mL}$ recombinant MIF for $24 \mathrm{~h}$, western blot assayed TGF- $\beta 1$ expression. All experiments were conducted independently at least three times. Error bars represent standard deviation. $\star \mathrm{P}<0.05$ compared with control group. $\mathrm{ZP}<0.05$ compared with MIF group. 

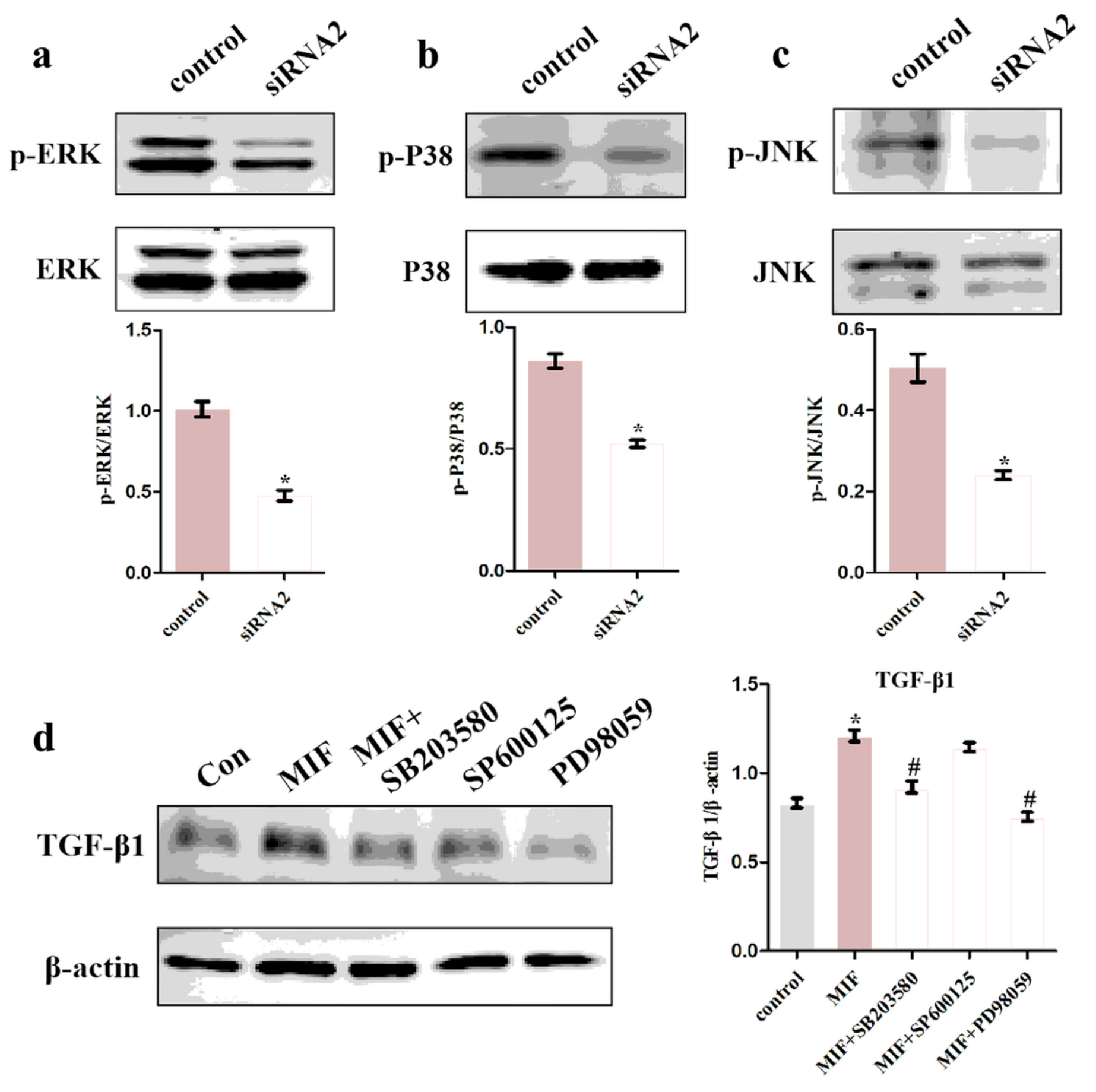

Figure 7

Determination of intracellular signaling associated with regulation of TGF- $\beta 1$ expression. a-c Western blot analysis of p-ERK(a), p-P38(b), and p-JNK(c) following joint capsule fibroblasts treated with siRNA2 or control siRNA for $48 \mathrm{~h}$ and then with $2 \mu \mathrm{g} / \mathrm{mL}$ recombinant MIF for $30 \mathrm{~min}$. $\mathrm{d}$ Joint capsule fibroblasts were pretreated with $10 \mu \mathrm{M}$ inhibitor of P38 (SB203580), JNK (SP600125), or ERK (PD98059) for $1 \mathrm{~h}$ before treatment with $2 \mu \mathrm{g} / \mathrm{mL}$ recombinant MIF for $24 \mathrm{~h}$, western blot assayed TGF- $\beta 1$ expression. All experiments were conducted independently at least three times. Error bars represent standard deviation. $\star \mathrm{P}<0.05$ compared with control group. $\mathrm{ZP}<0.05$ compared with MIF group. 

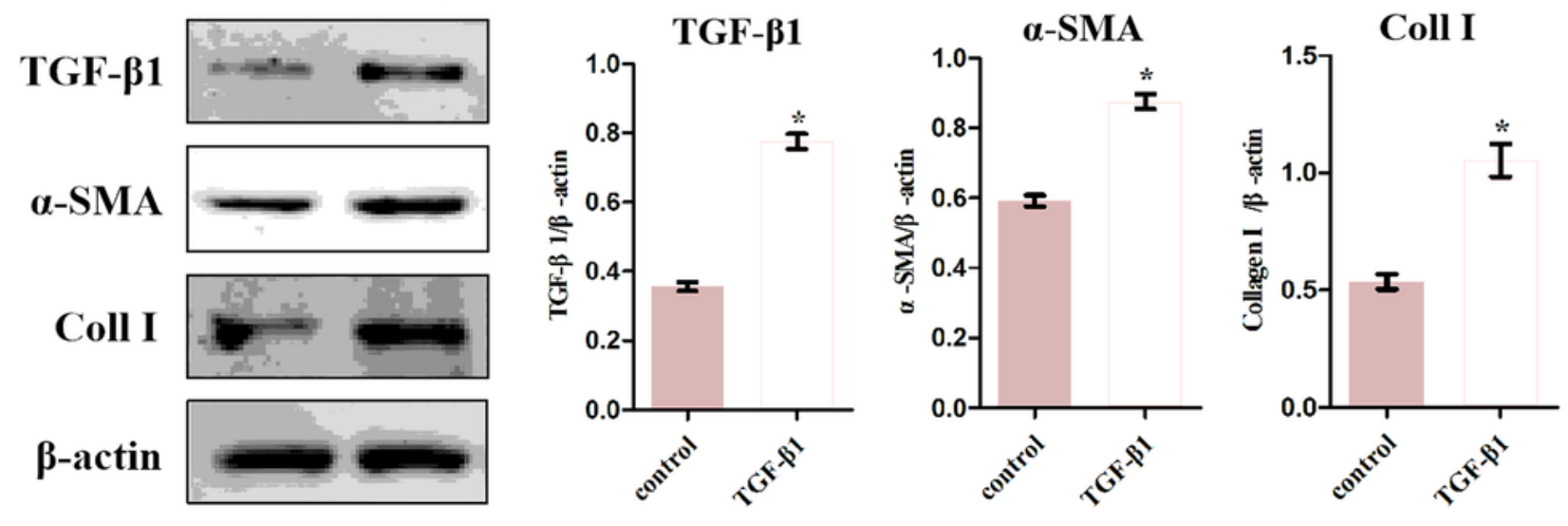

b

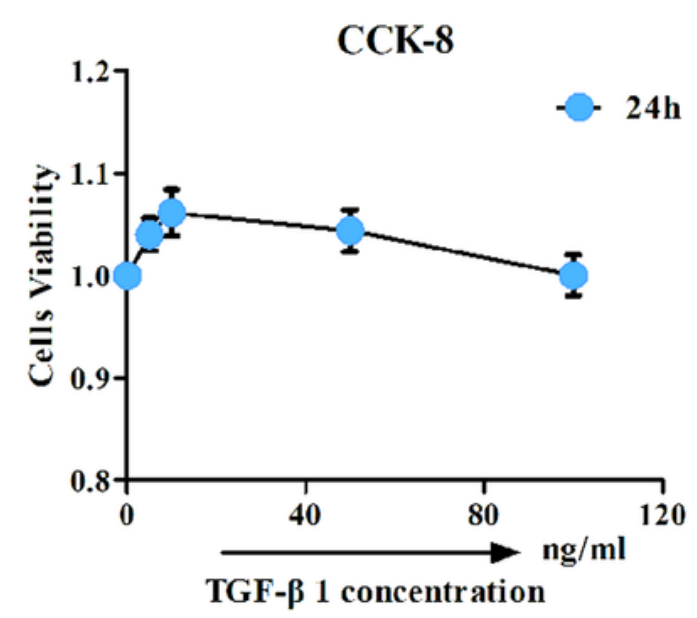

c

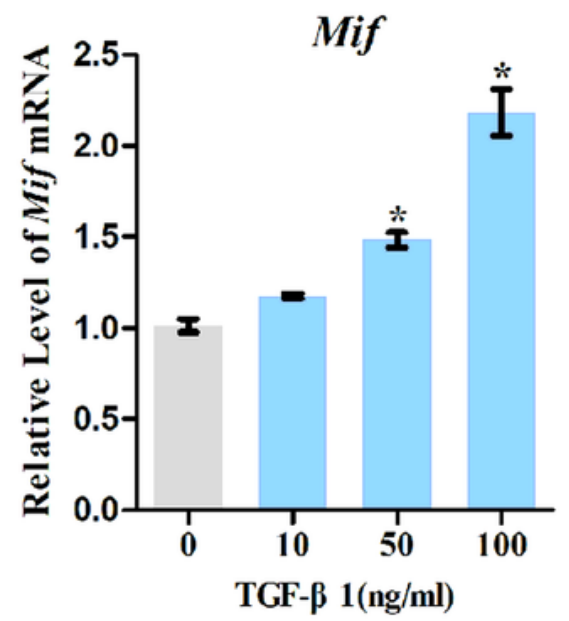

d
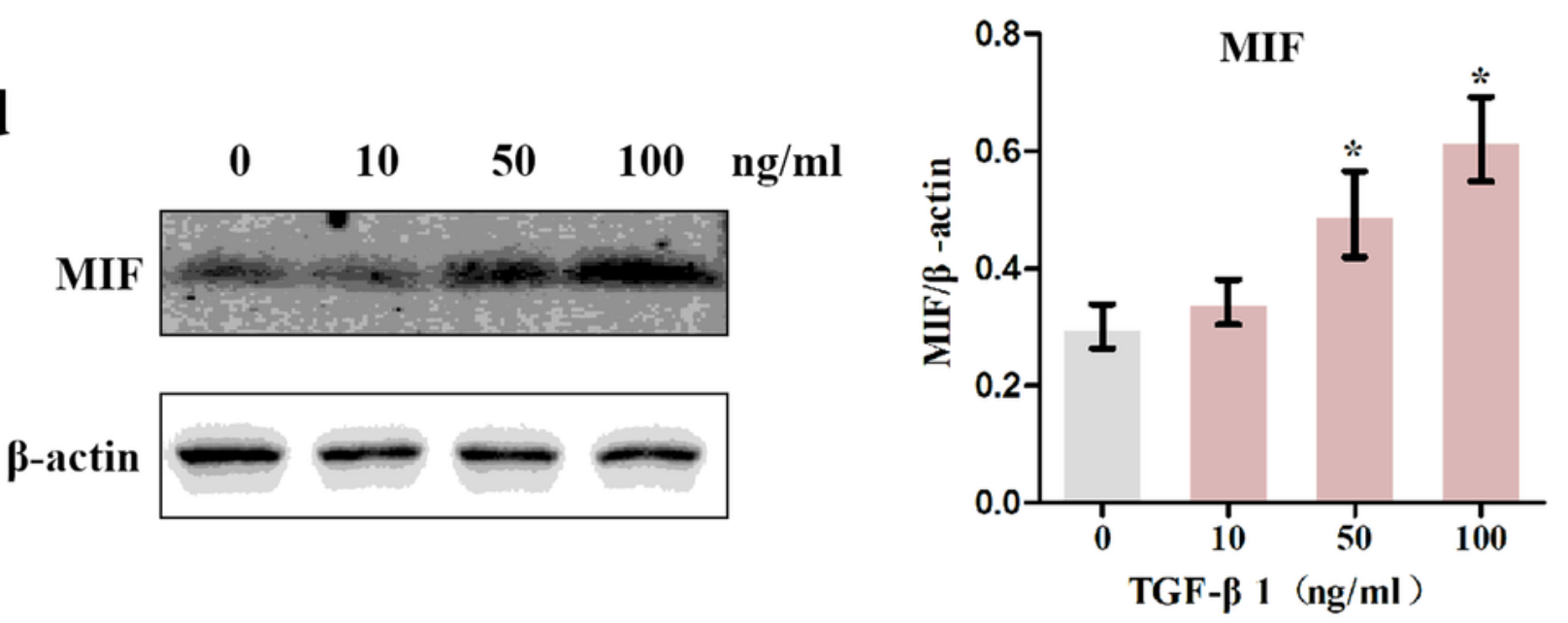

Figure 8

Effects of TGF- $\beta 1$ on the expression of pro-inflammatory and pro-fibrotic molecules. a Western blot analysis the expression of TGF- $\beta 1, a-S M A$, and Collagen $\triangle$ in joint capsule fibroblasts following treatment with $10 \mathrm{ng} / \mathrm{mL}$ recombinant TGF- $\beta 1$ for $24 \mathrm{~h}$. b CCK-8 assay was performed on joint capsule fibroblasts treated with varying TGF- $\beta 1$ concentrations. $c$, $d$ Expression of MIF were assessed by qRT-PCR (c) and western blot (d) following joint capsule fibroblasts treatment with $0-100 \mathrm{ng} / \mathrm{mL}$ recombinant TGF- $\beta 1$ for 
$24 \mathrm{~h}$. All experiments were conducted independently at least three times. Error bars represent standard deviation. ${ }^{*} \mathrm{P}<0.05$ compared with control group or $0 \mathrm{ng} / \mathrm{mL}$ group.

\section{a Con TGF- $\beta 1$}
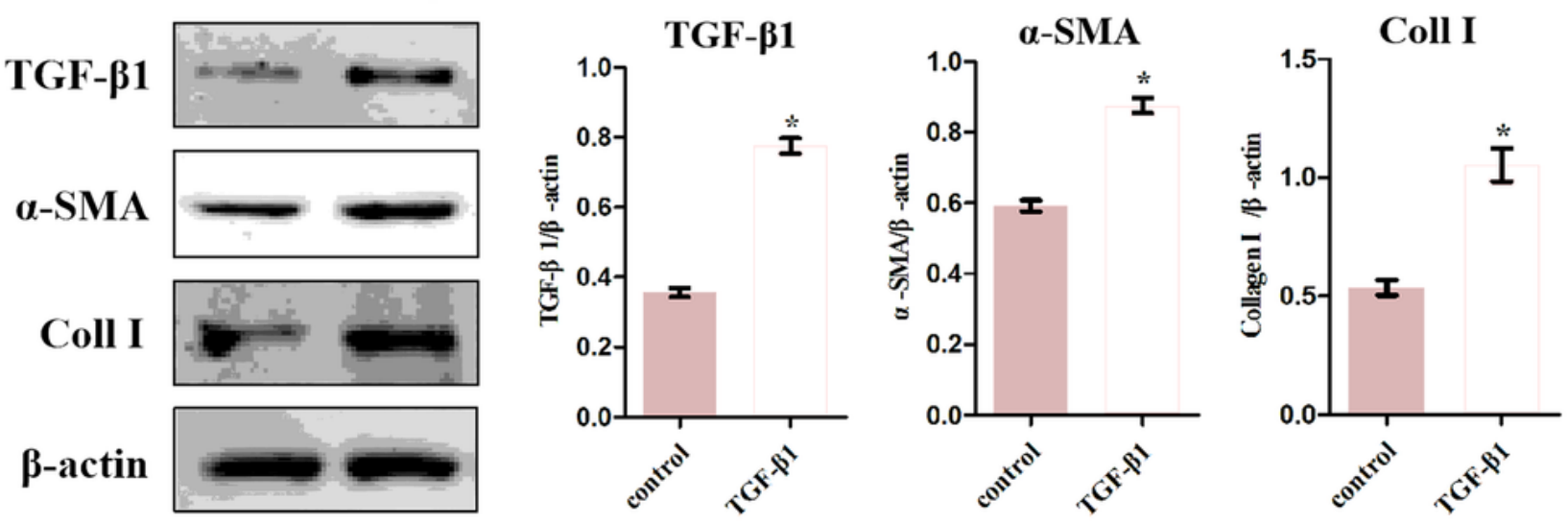

b

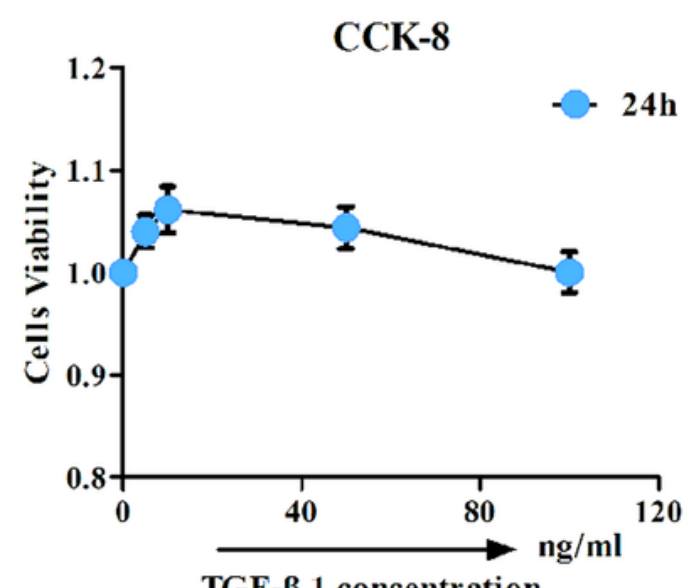

c

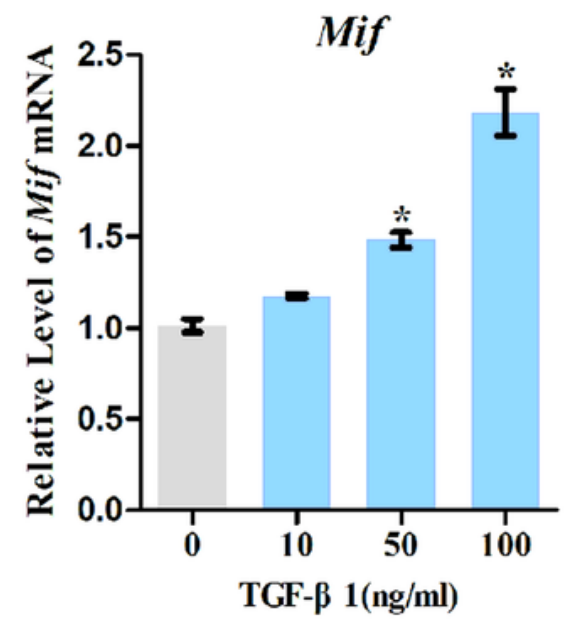

d
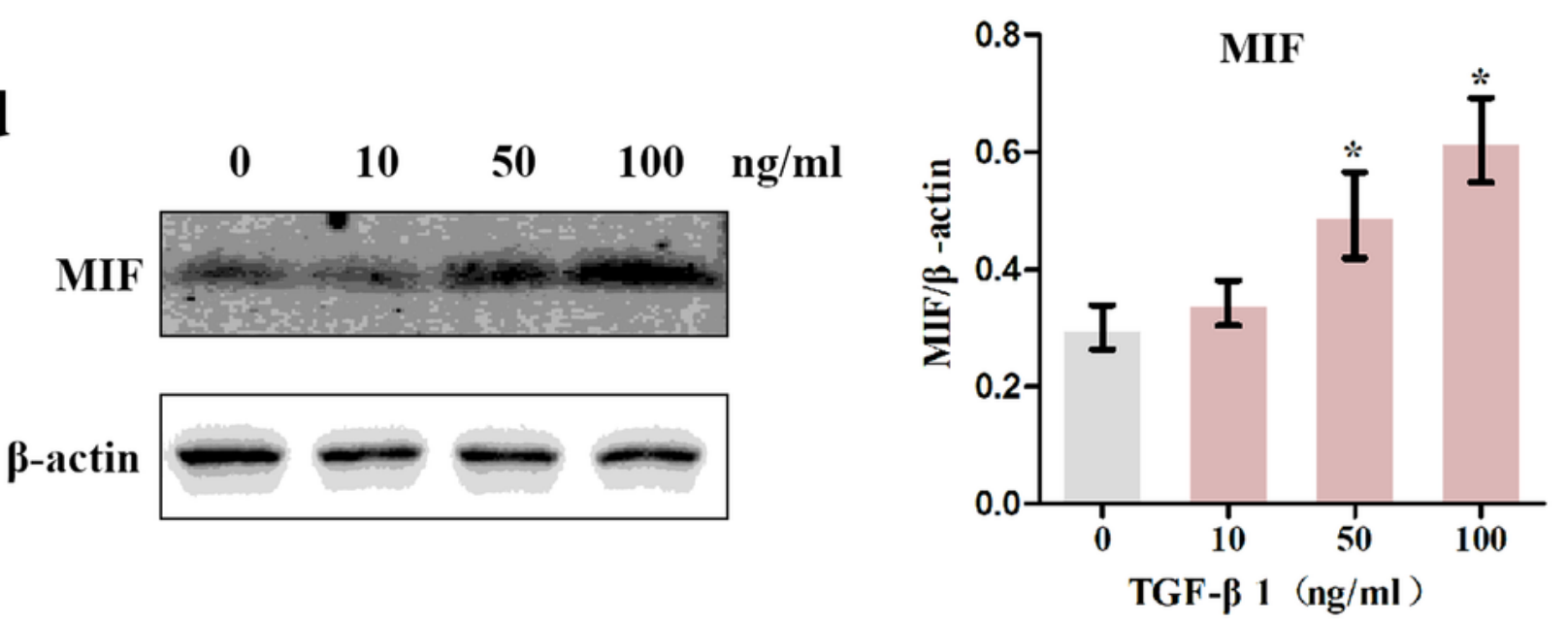

Figure 8

Effects of TGF- $\beta 1$ on the expression of pro-inflammatory and pro-fibrotic molecules. a Western blot analysis the expression of TGF- $\beta 1, a-S M A$, and Collagen $\otimes$ in joint capsule fibroblasts following treatment with $10 \mathrm{ng} / \mathrm{mL}$ recombinant TGF- $\beta 1$ for $24 \mathrm{~h}$. b CCK-8 assay was performed on joint capsule fibroblasts 
treated with varying TGF- $\beta 1$ concentrations. $c$, $d$ Expression of MIF were assessed by qRT-PCR (c) and western blot (d) following joint capsule fibroblasts treatment with $0-100 \mathrm{ng} / \mathrm{mL}$ recombinant TGF- $\beta 1$ for $24 \mathrm{~h}$. All experiments were conducted independently at least three times. Error bars represent standard deviation. ${ }^{*} \mathrm{P}<0.05$ compared with control group or $0 \mathrm{ng} / \mathrm{mL}$ group.

\section{Supplementary Files}

This is a list of supplementary files associated with this preprint. Click to download.

- Supplementaryinformation.doc

- Supplementaryinformation.doc 